IZA DP No. 9411

Identifying Sorting in Practice

Cristian Bartolucci

Francesco Devicienti

Ignacio Monzón

October 2015 


\title{
Identifying Sorting in Practice
}

\author{
Cristian Bartolucci \\ Collegio Carlo Alberto
}

Francesco Devicienti

University of Turin,

Collegio Carlo Alberto and IZA

Ignacio Monzón

Collegio Carlo Alberto

\section{Discussion Paper No. 9411 \\ October 2015}

\author{
IZA \\ P.O. Box 7240 \\ 53072 Bonn \\ Germany \\ Phone: +49-228-3894-0 \\ Fax: +49-228-3894-180 \\ E-mail: iza@iza.org
}

Any opinions expressed here are those of the author(s) and not those of IZA. Research published in this series may include views on policy, but the institute itself takes no institutional policy positions. The IZA research network is committed to the IZA Guiding Principles of Research Integrity.

The Institute for the Study of Labor (IZA) in Bonn is a local and virtual international research center and a place of communication between science, politics and business. IZA is an independent nonprofit organization supported by Deutsche Post Foundation. The center is associated with the University of Bonn and offers a stimulating research environment through its international network, workshops and conferences, data service, project support, research visits and doctoral program. IZA engages in (i) original and internationally competitive research in all fields of labor economics, (ii) development of policy concepts, and (iii) dissemination of research results and concepts to the interested public.

IZA Discussion Papers often represent preliminary work and are circulated to encourage discussion. Citation of such a paper should account for its provisional character. A revised version may be available directly from the author. 


\section{ABSTRACT}

\section{Identifying Sorting in Practice ${ }^{*}$}

We propose a novel methodology to uncover the sorting pattern in the labor market. Our methodology exploits the additional information contained in profits, which complements the information from wages and transitions typically used in previous work. We identify the strength of sorting solely from a ranking of firms by profits. To discern the sign of sorting, we build a noisy ranking of workers from wage data. We provide a test for the sign of sorting that is consistent even with noise in worker rankings. We apply our approach to a panel data set that combines social security earnings records for workers in the Veneto region of Italy with detailed financial data for firms. We find robust evidence of positive sorting. The correlation between worker and firm types is about $52 \%$.

JEL Classification: J6, J31, L2

Keywords: assortative matching, worker mobility, profits, matched employer-employee data

Corresponding author:

Francesco Devicienti

Dipartimento di Scienze Economico-Sociali e Matematico-Statistiche

Università di Torino

Corso Unione Sovietica 218bis

10134 Torino

Italy

E-mail: francesco.devicienti@unito.it

\footnotetext{
${ }^{*}$ We thank Ainhoa Aparicio Fenoll, Manuel Arellano, Stephane Bonhomme, David Card, Ben Cowan, Arnaud Dupuy, Jan Eeckhout, Pieter Gautier, Philipp Kircher, Francis Kramarz, Giovanni Mastrobuoni, Claudio Michelacci, Nicola Persico, Alfonso Rosolia, Paolo Sestito, Aleksey Tetenov, Aico van Vuuren and members of audiences at Arizona, the Bank of Spain, Berkeley, Bergen, Bocconi, CEPSINSTEAD, CEMFI, Collegio Carlo Alberto, EIEF, Tinbergen Institute, UAB, University of Melbourne, and UNSW for helpful comments. We are also extremely grateful to Giuseppe Tattara for making available the data set and to Marco Valentini and Carlo Gianelle for assistance in using it. Finally, we thank Emily Moschini for outstanding research assistance. The usual disclaimers apply.
} 


\section{Introduction}

What is the pattern of sorting of heterogeneous workers into heterogeneous firms? Do better workers typically work in better firms? In some labor markets, like academia, anecdotal evidence supports this idea. However, discerning the pattern of sorting in labor markets remains elusive. A direct analysis of sorting requires knowledge of the underlying types of both firms and workers, which is hard to obtain. In this paper, we propose a new strategy to identify the strength and sign of sorting.

Uncovering the actual patterns of assortative matching is key for the analysis of the labor market. In the presence of sorting, shocks and policies that affect firms do not necessarily affect workers evenly. For example, recessions and trade liberalization push low-productivity firms out of the market (see Caballero and Hammour [1994] and Melitz [2003]). The pattern of sorting sheds light on the transmission of these shocks. Under positive assortative matching, low skill workers are disproportionately affected by the resulting displacements. Moreover, Card, Heining, and Kline [2013] show that sorting plays an important role as a source of wage inequality. Furthermore, whenever sorting is driven by complementarity in production, the strength of sorting conveys information on the magnitude of the complementarity. Finally, revealing the sorting pattern allows for testing economic models which exhibit distinct sorting patterns in equilibrium. ${ }^{1}$

Ideally, one would observe worker and firm types to measure the sorting pattern. What makes one firm better than another? Firms are heterogeneous in several dimensions. The firm type combines a number of features related to technology, demand and market structure (Syverson [2011]). Firms differ in managerial talent and practices (e.g. Bloom and Van Reenen [2007]), organizational form (e.g. Garicano and Heaton [2010]), human resources practices (e.g. Ichniowski and Shaw [2003]), market power and technology spillovers (e.g. Bloom, Schankerman, and Van Reenen [2013]), sunk costs (e.g. Collard-Wexler [2013]), and span of control (e.g. Eeckhout and Kircher [2012]), among other dimensions. It is hard to find empirical counterparts for each of these characteris-

\footnotetext{
${ }^{1}$ Some models predict positive assortative matching (see Shimer [2005] or Lise, Meghir, and Robin [2013]), others negative assortative matching (e.g. Woodcock [2010]), and lastly some predict a random allocation of workers to firms (see Postel-Vinay and Robin [2002] or Bartolucci [2013]).
} 
tics. Moreover, even if they could be measured, aggregating them is far from straightforward.

Although different in several dimensions, firms share an objective function: they maximize profits. Profits aggregate the features that make firms heterogeneous into a natural one-dimensional ranking. Since all firms aim to maximize profits, better ones have higher profits. Moreover, the information needed to measure profits is publicly available and increasingly included in many data sets.

We rank firms by their profits. Previous work has focused on using wages alone to try to identify sorting. A basic rationale for using wages is that they contain information on underlying worker quality. Using profits to rank firms has two main advantages with respect to using wages to rank workers. First, the worker's objective function is more nuanced than the firm's. Salaries are important, but several non-pecuniary components also enter into the worker utility function. Part of the variation in wages is driven by compensating differentials. Second, firms are matched to a large number of workers, while workers typically only have a few employers in their work history. Because of frictions, both workers and firms may accept less than ideal matches. Then, part of the variation in per-match wages and profits is due to realized partner types. Furthermore, variation in per-match payoffs is also driven by other factors, such us renegotiation, heterogeneity in search intensity, or match effects. Fortunately, since firms are observed with many partners, total profits integrate out match-specific heterogeneity.

To estimate the pattern of sorting, we use firm-level data on profits to rank firms and worker-level data on wages to construct a noisy ranking of workers. We exploit a unique panel data set that combines social security earnings records and labor market histories for individual workers in the Veneto region of Italy with detailed financial data for their employers. This data set is especially suited to our application since it contains not only the universe of incorporated businesses in the region but also information on every single employee working in these firms.

Our first contribution is to provide a methodology to measure the strength of sorting without the need to rank workers. We define the strength of sorting by the correlation ratio $\eta$, which measures the variance of firm types that can be explained by worker types. Intu- 
itively, the more intensively workers sort into firms, the smaller the variance of partners' types for a given worker, compared to the unconditional variance of firm types. Empirical attempts to identify the strength of sorting have focused on the correlation coefficient $\rho$ between firm and worker types (e.g. Abowd, Kramarz, and Margolis [1999] or Bagger and Lentz [2014]). When the expected employer type is a linear function of the worker's type, $\rho^{2}$ and $\eta^{2}$ coincide. We focus on the correlation ratio since it does not impose linearity.

We estimate the correlation ratio through information contained in observations of the same worker matched to different firms. We use standard panel data techniques to separate out permanent from transitory components in the variation of employer types. The variation of the transitory component, or within worker variation of partners, is the variation of firm types not explained by the worker type. We find that worker types explain around $27 \%$ of the variance in employer types in our data set. This corresponds to a correlation ratio of $52 \%$.

Our second contribution is to provide a simple test for the sign of sorting. The strength of sorting provides a measure of the association between firm and worker types, but remains silent about its direction. If worker types were observed, the sign of the correlation between worker and firm types would reveal the direction of sorting. We use wages to rank workers, but acknowledge that wages only provide a noisy ranking of workers. When the noise is orthogonal to worker and firm types, the correlation between worker and firm types is attenuated. A major concern in our case is that wages paid by a firm are potentially correlated with the firm type. We rely on the availability of independent draws from a worker's distribution of employers to obtain an attenuated estimate of the correlation between worker and firm types. The intuition underlying our empirical strategy is simple. Take two workers with transitions mediated by unemployment. Wages received in the new firms are independent of employer types before unemployment. Then, our strategy to identify the sign of sorting relies on the correlation between employer types before unemployment and wages obtained after the unemployment spell.

The presence of attenuation is not detrimental to our empirical strategy, as our test only needs to establish the sign of the correlation between worker and firm types. We consider and discard a number of potential additional threats to attenuation. First, we 
restrict the variation of wages to observationally equivalent workers. Second, we compare coworkers partialling out between-firm heterogeneity in compensating differentials. Third, we relax most of the constraints required for attenuation in the specification of the empirical model, such as linearity in the association between worker and firm types and additive separability of the noise. We do so by estimating the direction of sorting nonparametrically using Kendall's rank correlations. We find that the Kendall coefficient is positive and significant. Moreover, we show that attenuation can be guaranteed for the Kendall coefficient under milder conditions than those needed in its parametric counterpart.

Our tests build on standard panel-data techniques. The small number of partners for each worker prevents the consistent estimation of worker-specific parameters. This is analogous to the incidental parameter problem in applications of panel data with a short longitudinal dimension. Although we cannot consistently estimate the expected employer type for each worker, we can consistently estimate its variance, which we use to estimate the strength of sorting. In order to estimate the sign of sorting, we also follow standard panel-data techniques, where lags and leads of the regressors are used to solve problems of endogeneity.

We present a large set of robustness checks for our results. First, we challenge our baseline ranking of firms. Our results are robust to various alternative definitions of profits that we observe for each firm: economic profits, accounting profits, or gross operating margins and return over equity. Second, we allow for on-the-job search and for correlation between employer types before and after unemployment. In our baseline specification, we assume that partners after unemployment are random draws from the steady state distribution. However, workers may be less selective when unemployed if they can search while matched. Moreover, partner types before and after unemployment may be correlated, e.g. whenever workers exploit a network of previous coworkers to find new jobs. Our results are robust to these modifications. Third, we account for endogenous mobility. In our baseline specification we only use workers who transit unemployment and consider match destruction as exogenous. The sample of workers transiting unemployment and the sample of firms firing workers are potentially selected. We take into 
account both sources of selection and show that our results do not differ significantly.

\subsection{Related Literature}

The theoretical literature on sorting focuses mainly on how complementarity in production determines the allocation of workers to firms. In his seminal paper, Becker [1973] studies a frictionless economy and shows that positive sorting arises if and only if the production function is supermodular. Shimer and Smith [2000] extend Becker's model to account for search frictions, and show that stronger complementarities in the production function are required to guarantee positive sorting. Atakan [2006] explicitly models search costs and provides sufficient conditions that restore Becker's classical result. In Eeckhout and Kircher [2010] root-supermodularity is necessary and sufficient for positive sorting. Bartolucci and Monzón [2014] allow for bilateral on-the-match search and show that positive sorting can arise even without complementarity in production.

Following the seminal contribution of Abowd et al. [1999], several papers attempt to measure the direction and strength of sorting through the correlation between the worker fixed effect and the firm fixed effect estimated from wage equations. The usual finding is that this correlation is insignificant or even negative, implying that positive assortative matching plays little role in the labor market. Gautier and Teulings [2006], Eeckhout and Kircher [2011], Lopes de Melo [2013], and Bagger and Lentz [2014] argue that the strategy in Abowd et al. [1999] is misspecified. In particular, whenever wages are non-monotone in the firm type (or there are amenities), worker and firm fixed effects estimated from wage equations do not necessarily reflect the agents' underlying types. Furthermore, wages only provide a noisy ranking of workers due to the small number of partners over the life-cycle. We report on the performance of Abowd et al.'s exercise in our data (see Apendix A.7). We obtain a negative and small correlation between the firm fixed effect and the worker fixed effect. Taken at face value, these results would be consistent with the existence of negative sorting, which is the opposite of what we find using our method.

Our paper contributes to a growing literature aiming at overcoming the limitations 
of Abowd et al.'s approach to measuring sorting. ${ }^{2}$ Eeckhout and Kircher [2011] and Lopes de Melo [2013] propose methods to measure the strength of sorting, but remain silent on its sign. Eeckhout and Kircher [2011] suggest using information on the range of accepted wages of a given worker. Lopes de Melo [2013] relies on the correlation between a worker fixed effect estimated from a wage equation and the average fixed effects of her coworkers. ${ }^{3}$ Mendes, van den Berg, and Lindeboom [2010] identify both the strength and sign of sorting, under the assumption that a worker's type can be identified from a set of observable characteristics. They focus on the correlation between the firm fixed effect estimated from a production function equation and the (observed) skill level of the firm's workforce. ${ }^{4}$

In recent working papers, Hagedorn, Law, and Manovskii [2012] and Bagger and Lentz [2014] structurally estimate fully specified models to recover the sign and strength of sorting. Structural estimation implies a trade-off: it allows for the identification of sensible primitives such as the degree of complementarity in the production function, but at the cost of a loss of generality. The present paper presents results for the strength and sign of sorting without relying on one specific model of the labor market. Our methodology exploits the additional information contained in profits, which complements the information from wages and transitions typically used in the literature. In Hagedorn et al. [2012] the rankings of both workers and firms are constructed from wages. However, observed wages have sources of variation other than worker and firm types. Consistency of the results presented in Hagedorn et al. [2012] is not guaranteed if part of the variation in wages comes from compensating differentials (amenities), renegotiation, match effects or any form of non-classical measurement error. ${ }^{5}$ Our methodology to identify the strength

\footnotetext{
${ }^{2}$ We focus on one-dimensional sorting. For multidimensional sorting see Dupuy and Galichon [2014] and Lindenlaub [2014].

${ }^{3}$ Lopes de Melo [2013] shows that in a search model with on-the-job search, a supermodular production function and job scarcity, his proposed measure works better than Abowd et al.'s correlation. He applies his method to matched employer-employee data from Brazil, finding evidence of assortative matching.

${ }^{4}$ Mendes et al. [2010] find evidence of positive assortative matching using Portuguese longitudinal data. Unfortunately there is strong evidence (see for example Lillard and Weiss [1979], Hause [1980] or Meghir and Pistaferri [2004]) suggesting that observable characteristics are not sufficient statistics for workers' unobserved fixed heterogeneity.

${ }^{5}$ Hagedorn et al. [2012] present simulations on the robustness of their results under i.i.d. shocks which are additive in wages. Unfortunately, several sources of variation in wages are not necessarily additively separable. There are many environments where this assumption does not hold. To mention only two cases:
} 
of sorting does not rely on wages, and our strategy to detect the sign of sorting is robust to the use of noisy rankings of workers obtained from wages.

In the next section we describe our data set. In Section 3 we define the strength and sign of sorting, and discuss how to use our data set to build a global ranking of firms and noisy rankings of workers. Section 4 presents our methodology and results for the strength of sorting. In Section 5 we show how to consistently estimate the sign of sorting. Section 6 contains robustness checks. Section 7 concludes.

\section{Data}

We build our data set by combining information from two different sources: individual labor market histories and earnings records, and firm financial data. ${ }^{6}$ The job histories and earnings data are derived from the Veneto Workers History (VWH) data set, constructed by a team led by Giuseppe Tattara at the University of Venice, from administrative records of the Italian Social Security System. The VWH contains information on private sector employees in the Veneto region of Italy over the period from 1975 to 2001 (see Tattara and Valentini [2007]). ${ }^{7}$ Specifically, it includes register-based information for any job that lasts at least one day. On the employee side, the VWH includes total earnings during the calendar year for each job, the number of days worked during the year, the code of the appropriate collective national contract and level within that contract, and the worker's gender, age, region (or country) of birth, and seniority with the firm. On the employer side the VWH includes industry (classified by 5-digit ATECO 91), the dates of "birth" and closure of the firm (if applicable), the firm's location, and the firm's national tax number (codice fiscale).

Our balance sheet data are derived from standardized reports that firms are required to file annually with the Chamber of Commerce. ${ }^{8}$ These data are distributed as the

measurement error is typically assumed to be additively separable in log-wages, but not in wages; and renegotiation on wages does not add additively separable noise in general (not even within the firm, see Postel-Vinay and Robin [2002]).

${ }^{6}$ Card, Devicienti, and Maida [2014] use this data set to investigate the extent of rent-sharing and holdup in firms' investment decisions.

${ }^{7}$ The Veneto region has a population of about 4.6 million, approximately $8 \%$ of Italy's total population.

${ }^{8}$ These data are known as the Company Register Database (Registro delle Imprese). Italian Law 580 of 
"AIDA" database by Bureau van Dijk, and are available from 1995 onward for firms with annual sales above 500, 000 Euros. In principle, all (non-financial) incorporated firms with annual sales above this threshold are included in the database. The available data contain all entries of the standardized balance sheet and of the profit and loss accounts (including sales, value added, total wage bill, the book value of capital - broken down into a number of subcategories, the total number of employees, industry - categorized by 5-digit code, and the firm's national tax number). ${ }^{9}$

We use tax code identifiers to match job-year observations for employees in the $\mathrm{VWH}$ to employer information in AIDA for the period from 1995 to 2001. We carry out additional checks of business names (ragione sociale) and firm locations (firm addresses) in the two data sources to minimize false matches. The match rate is relatively high: for about $95 \%$ of the AIDA firms we find a matching firm in the $\mathrm{VWH} .{ }^{10}$

Balance-sheet data is less accurate for small firms. For this reason we discard observations at firms with fewer than 10 employees. We report the characteristics of our initial sample in column (1) of Table 1. Over the 1995-2001 period, the matched data set contains about 840,000 individuals aged 16-64, observed in about 1 million job spells (about 3 million job $\times$ year observations) at over 23,000 firms. ${ }^{11} 29 \%$ of workers in the sample are female, $30 \%$ are white collar and a tiny minority, about $1 \%$, are managers. The mean age is 35 , mean tenure is 103 months and the mean daily wage is 69 Euros. The mean firm

1993 established the Chamber of Commerce as the depository for standardized financial and balance sheet data for all incorporated firms in Italy.

${ }^{9}$ See http://www.bvdinfo.com/en-gb/our-products/company-information/national-products/aida. Only a tiny fraction of firms in AIDA are publicly traded. We exclude these firms and those with consolidated balance sheets (i.e., holding companies).

${ }^{10}$ The quality of the matches is further evaluated by comparing the total number of workers in the VWH who are recorded as having a job at a given firm (in October of a given year) with the total number of employees reported in AIDA (for the same year). In general the two counts agree very closely. Total wages and salaries for the calendar year as reported in AIDA were compared with total wage payments reported for employees in the VWH. The two measures are highly correlated (correlation > 0.98). See Card et al. [2014].

${ }^{11}$ Firms in the sample represent about $10 \%$ of the total universe of firms contained in the VWH. The vast majority of the unmatched firms are non-incorporated, small family business (società di persone) that are not required by existing regulations to maintain balance sheets books, and are therefore outside the AIDA reference population. The average firm size for the matched sample of incorporated businesses is significantly larger than the size of non-incorporated businesses. Mean daily wages for the matched sample are also higher than in the entire $\mathrm{VWH}$, while the fractions of female and younger workers are lower. See Card et al. [2014] for further details. 
size is 58 employees.

The bottom panel of Table 1 reports the mean values of several measures of profits regularly used in the literature. Most of our results are based on economic profits, given by $\Pi_{j t}=Y_{j t}-M_{j t}-w_{j t} L_{j t}-r_{t} K_{j t}$, where $Y_{j t}$ denotes total sales of firm $j$ in year $t, M_{j t}$ stands for materials and $w_{j t} L_{j t}$ are firm labor costs, all as reported in the firm's profit and loss account. To deduct capital costs, we compute $K_{j t}$ as the sum of tangible fixed assets (land and buildings, plant and machinery, industrial and commercial equipments) plus immaterial fixed assets (intellectual property, R\&D, goodwill). ${ }^{12}$ We assume that $r_{t}=10 \%{ }^{13}$

Although we present our discussion in terms of economic profits, our results are robust to the choice of the measure of profits. Through the paper, we report results based on gross operating surplus (GOS), which does not deduct estimated capital costs. We also consider accounting net profits (AP), obtained from GOS after deducting taxes and debt service, and adding any financial income and extraordinary revenues (e.g., income deriving from subsidiaries or other equity investment owned by the firm, rather than from its core business). These measures of profits are either used in levels or normalized by the number of workers employed by the firm. As an alternative normalization, we also consider the return on equity (ROE), defined by the ratio of AP to shareholder's funds. To minimize the impact of short-term fluctuations and measurement error, we average each profit definition longitudinally, i.e. over all years in which a firm is observed in our sample. As shown by Table 1, the average economic profit is about 500, 000 Euros (in 2000 prices), and profit per worker is 12,000 Euros. The corresponding figures for the GOS are slightly higher, and lower for AP. On average, firms have a ROE of about $7 \%$.

\footnotetext{
${ }^{12}$ Capital is measured as the book value of past investments in the AIDA data. Recomputing a firm's capital based on the perpetual inventory method (see Card et al. [2014]) does not modify our results.

${ }^{13}$ The literature on capital investment in Italy suggests that during the mid-to-late 1990s a reasonable estimate of the user cost of capital $\left(r_{t}\right)$ is in the range of $8 \%$ to $12 \%$. Elston and Rondi [2006] report a distribution of estimates of the user cost of capital for publicly traded Italian firms in the 1995-2002 period, with a median of $11 \%$ (Elston and Rondi [2006], Table A4). Arachi and Biagi [2005] calculate the user cost of capital, with special attention to the tax treatment of investment, for a panel of larger firms over the 1982-1998 period. Their estimates for $1995-1998$ are in the range of $10 \%$ to $15 \%$ with a value of $11 \%$ in 1998 (Arachi and Biagi [2005], Figure 2). Franzosi [2008] calculates the marginal user cost of capital taking into account the differential costs of debt and equity financing, and the effects of tax reforms in 1996 and 1997. Her calculations suggest that the marginal user cost of capital was about $7.5 \%$ pre- 1996 for a firm with $60 \%$ debt financing, and fell to 6\% after 1997.
} 
We make a series of exclusions to arrive at the sample of transitions that we use for estimating the strength and sign of sorting. First, we consider only those workers who within the 1995-2001 period - ever switched from a firm in the data set to another firm in the data set, with or without an intervening spell of unemployment. Second, we eliminate apprentices and part-time employees.

We report the characteristics of the workers and the firms included in this first sample of transitions in column (2) of Table 1. There are around 168,000 job switchers in the sample (or some $20 \%$ of the original sample), moving between almost 12,000 firms, for a total of 228,590 transitions. Of those, 178, 219 are transitions mediated by at least one month of non-employment. ${ }^{14}$ As expected, job changers are on average younger than the overall sample (their mean age is 32 years), have lower tenure (less than 3 years) and earn comparatively less than the rest of the population (66 Euros daily). The percentage of female workers, white collar workers and managers are also smaller in the job changer sample than in the overall sample of column (1). The table also reports the number of months that have elapsed between the separation from the former employer and the association with the new one. The median duration of this interim unemployment is only 3 months. However, the mean unemployment duration is 8.3 months, which is consistent with a large fraction of workers with long-term unemployment (ISTAT [2000]). We use the sample reported in column (2) to estimate the strength of sorting.

To test for the sign of sorting we use the more restricted sample of movers shown in column (3). Our test of the sign of sorting - unlike our procedure for estimating the strength of sorting - requires information on workers' wages. Hence, to minimize measurement error in wages we further restrict the sample to workers with a minimum of labor market attachment. ${ }^{15}$ We also eliminate unusually high wages by dropping wages

\footnotetext{
${ }^{14}$ As discussed in our description of the institutional background in Appendix A.1, the Italian labor market is characterized by enough wage variability and worker mobility to make our empirical strategy viable.

${ }^{15}$ We aim at excluding observations that may reflect things other than jobs (reimbursements, for example). We discard observations if the job duration is lower than 26 days. Similarly, we discard observations with unreasonably low wages. We take the "minimum wage" for the lowest category in each "national contract". We in turn calculate the lowest of all those "minimum wages". Any wage lower than that is discarded (this roughly corresponds to the bottom $1 \%$ of the wage distribution). Information about contractual minimum wages (inclusive of any cost-of-living allowance and other special allowances) was obtained from records of the sector-wide national contracts.
} 
Table 1: Descriptive Statistics: VWH - AIDA

\begin{tabular}{|c|c|c|c|}
\hline & $\begin{array}{l}\text { Complete } \\
\text { Sample } \\
\text { (1) }\end{array}$ & $\begin{array}{l}\text { Job-changer } \\
\text { Sample } \\
\text { (2) }\end{array}$ & $\begin{array}{c}\text { Job-changer Sample } \\
\text { (sign of sorting) } \\
\text { (3) }\end{array}$ \\
\hline Number of Jobs $\times$ Year obs & $3,073,672$ & & \\
\hline Number of Individuals & 837,904 & 168,280 & 97,455 \\
\hline Number of Firms & 23,448 & 11,907 & 9,228 \\
\hline Number of Jobs & $1,057,901$ & & \\
\hline $\begin{array}{l}\text { Number of Transitions } \\
\text {...of which through at least }\end{array}$ & & 228,590 & 156,213 \\
\hline one month of unemployment & & 178,219 & 120,426 \\
\hline Worker Characteristics & & & \\
\hline Mean Age & 35.25 & 32.1 & 31.9 \\
\hline$\%$ Female & 0.29 & 0.25 & 0.28 \\
\hline$\%$ White Collar & 0.30 & 0.27 & 0.26 \\
\hline$\%$ Manager & 0.01 & 0.007 & 0.005 \\
\hline Mean Tenure $^{a}$ & 102.82 & 33.68 & 36.48 \\
\hline Mean Daily Wage & 69.35 & 66.03 & 59 \\
\hline Mean Daily log Wage & 4.12 & 4.03 & 4.02 \\
\hline Mean Interim Unemployment ${ }^{a}$ & & 8.29 & 7.90 \\
\hline Median Interim Unemployment ${ }^{a}$ & & 3 & 3 \\
\hline Firm Characteristics & & & \\
\hline Mean Firm Size & 58 & 62.21 & 69.4 \\
\hline Mean Profit ${ }^{b}$ & 503.12 & 587.48 & 781.4 \\
\hline Mean Profit per Worker ${ }^{b}$ & 11.75 & 12.04 & 11.49 \\
\hline Mean GOS ${ }^{b}$ & 656.15 & 765.22 & 1035.76 \\
\hline Mean GOS per Worker ${ }^{b}$ & 15.03 & 15.34 & 14.75 \\
\hline Mean $\mathrm{AP}^{b}$ & 184.24 & 202.21 & 261.3 \\
\hline Mean AP per Worker ${ }^{b}$ & 4.38 & 4.73 & 2.76 \\
\hline Mean Return over Equity & 0.07 & 0.07 & 0.07 \\
\hline
\end{tabular}

higher than the 99th percentile of the overall wage distribution. Finally, our main estimates of the sign of sorting are based on regressions that include firm fixed effects. This further restricts the estimation sample to firms with at least two movers. There are around 97, 000 job switchers in the sub-sample in column (3), moving between 9,000 firms, for a total of 156, 213 transitions. Of these, 120,426 are transitions mediated by at least one month of non-employment. The samples in column (2) and (3) are nevertheless very similar in terms of workers' and firms' characteristics. 


\section{Rankings and Definition of Strength and Sign of Sorting}

Intuitively, there is sorting when firm and worker types are associated. Sorting is positive when better firms are more often matched to better workers, and negative if it is the opposite way. Let heterogeneity be summarized by a one-dimensional index $p \in[0,1]$ for the firms, and $\varepsilon \in[0,1]$ for the workers. Assume that the distribution of matches $\ell(\varepsilon, p)$ has well defined conditional distributions and is in steady state.

We define the strength of sorting as the variance of firm types that can be explained by worker types. The variance of partners $\operatorname{var}[p \mid \varepsilon]$ for a given worker of type $\varepsilon$ is the variance of firms unexplained by $\varepsilon$. Therefore, a standard variance decomposition, $\sigma_{p}^{2}=\operatorname{var}[E[p \mid \varepsilon]]+E[\operatorname{var}[p \mid \varepsilon]]$, provides a sensible measure of the strength of sorting. The smaller the variance of partner's types for a given worker type relative to the unconditional variance of firm types, the more intensively workers sort into firms.

Definition 1 (Strength of Sorting) The strength of sorting is characterized by the correlation ratio $\eta=\sqrt{\operatorname{var}[E[p \mid \varepsilon]] / \sigma_{p}^{2}}$.

The strength of sorting is commonly associated with the correlation coefficient $\rho$ between firm and worker types (e.g. Abowd et al. [1999] or Bagger and Lentz [2014]). When the expected employer type $E[p \mid \varepsilon]$ is a linear function of worker type, $\rho^{2}$ and $\eta^{2}$ coincide. ${ }^{16}$ In Becker's symmetric model without frictions [1973], workers match only with firms of their same type (in case of positive assortative matching). Thus, $E[p \mid \varepsilon]$ is trivially linear in worker type. However, even stylized models of the labor market with frictions (e.g. Shimer and Smith [2000] or Atakan [2006]) do not imply that $E[p \mid \varepsilon]$ is linear in $\varepsilon$. We focus on the correlation ratio because it does not impose linearity on $E[p \mid \varepsilon]$.

The strength of sorting $\eta$ provides a measure of the association between firm type $p$ and worker type $\varepsilon$. However, $\eta$ cannot reveal the sign of sorting. Is there in fact positive assortative matching? If so, is it observed for the whole support of firms? From an empirical perspective, the sign of sorting has typically been associated to the sign of the

\footnotetext{
${ }^{16}$ The correlation ratio is by definition asymmetric and weakly greater than the correlation coefficient (which is symmetric). $\rho^{2}$ reveals the proportion of the variance of firm types explained by the best linear prediction from the worker types. See Kruskal [1958] for a discussion on the relationship between different measures of association.
} 
correlation coefficient between firm and worker types. Following our definition of the strength of sorting, we focus on the expected employer type.

Definition 2 (Sign of Sorting) There is positive sorting if $E[p \mid \varepsilon]$ is strictly increasing in $\varepsilon$. Negative sorting is defined analogously.

Theoretical work has focused on several different concepts to define positive sorting. The definition of sorting in Becker's frictionless model [1973] requires all mass to be concentrated in the $45^{\circ}$ degree line. If true, there is also positive sorting given our definition. In Shimer and Smith [2000], sorting is defined in terms of acceptance sets (from unemployment). There is (strict) positive sorting whenever acceptance sets are convex and feature (strictly) increasing bounds. Since there is no on-the-job search in Shimer and Smith [2000], acceptance sets from unemployment are the only determinants of the steady state distribution. If there is sorting in Shimer and Smith's model, given their definition, there is sorting given our definition. Chade [2006] (with imperfect information about types) and Lentz [2010] (with on-the-job search) define sorting in terms of stochastic dominance. Of course, first order stochastic dominance implies sorting given our definition.

The main challenge in the empirical analysis of sorting is that types $p$ and $\varepsilon$ are in principle unobserved. We tackle this challenge with a rich data set and a novel identification strategy.

\subsection{Ranking Firms}

The partnership model (one firm matched to only one worker) with productivity as the only source of heterogeneity between firms is canonical in the theory of sorting (see for example Shimer and Smith [2000], Atakan [2006], and Bartolucci and Monzón [2014]). However, firms are heterogeneous in several dimensions. To begin with, firms differ significantly in the number of workers they employ. A firm may be better because of its ability to manage a higher number of workers, even keeping output per worker constant. Moreover, firms also differ in their market power. Two firms with the same output per worker and the same span of control may be able to charge different prices to consumers. 
Again, the one which manages to charge a higher price does better. These are just examples of the several dimensions in which firms are heterogeneous.

We take advantage of the common objective function of firms to rank them. Profits aggregate the different dimensions of firms heterogeneity into a natural one-dimensional ranking. Consider two firms with the same number of workers. One has a higher output per worker but less market power than the other. Since both aim to maximize profits, the better one is the one with the higher profits.

In markets with frictions, firms accept less than ideal workers. For a given firm, some matches are more profitable than others. Therefore, match-level profits by themselves lead to a noisy ranking of firms. Luckily, firms are matched to a large number of workers (the data set we use has a mean firm size of 58 and only includes firms with at least 10 workers) and we observe profits at the firm-level. Thus, the sum of the profits per match integrates out match-specific heterogeneity. ${ }^{17}$

Idiosyncratic shocks to firms may also generate noise in our ranking of firms. However, the within-firm variation in profits accounts for only $7.63 \%$ of the total variation in profits in our sample. We average profits in the longitudinal dimension and each firm is observed on average for 5.35 years. Therefore, noise in the measurement of profits has a negligible effect on our results. ${ }^{18}$

To sum up, average profits per firm provide an observable global ranking of firms that aggregates several dimensions of heterogeneity. We report our results using many alternative definitions of profits, and obtain very similar results.

\footnotetext{
${ }^{17}$ In Shimer and Smith's model [2000], expected profits increase in firm type, but expected profits conditional on a vacancy being filled may not increase in firm type. Some firms may compensate lower profits (per realized match) with shorter vacancy times (see Hagedorn et al. [2012] for a discussion). Thus in Shimer and Smith's setup, where each firm only hires one worker, if firms are only observed while matched, profits may not rank firms. Luckily, we deal with multi-worker firms in our data set. Multi-worker firms are matched to their steady state distribution of partners and have their steady state proportion of empty slots. When firms only differ in terms of productivity, any two firms can hire up to the same number of workers. Therefore, since the flow payoff of a vacancy is zero, firms with the same maximum size can be ranked by their aggregated profits. If firms also differ in terms of capacity, our previous discussion on how to collapse many sources of heterogeneity applies.

${ }^{18}$ The within-firm variance of average profits is of order $1 / T_{j}$ of the variance of the idiosyncratic shocks, where $T_{j}$ is the number of periods that firm $j$ is observed. For example, for a firm observed in 5 periods, idiosyncratic shocks account for slightly more than $1 \%$ of the variance of average profits. We replicate results only including firms observed for more than $T$ periods, with $T \in\{1, \ldots, 5\}$. Results do not change significantly.
} 


\subsection{Ranking Workers}

Mean wages have been proposed and used to rank workers. Abowd et al. [1999] order workers using a fixed effect in a wage equation. Eeckhout and Kircher [2011] propose ranking workers by their mean wages. The rationale is analogous to that of our ranking of firms. A better worker should have a better performance in the labor market. If workers only cared about wages, mean wages would provide a valid ranking of workers according to their types.

However, workers' objective function is subtler than that of firms. Workers do care about wages, but also about non-pecuniary job characteristics, which are not captured by wages. Therefore, even if mean wages were observable, they would only provide a noisy ranking of workers. Moreover, we only observe a limited number of draws from the steady state distribution of wages for each worker. The small number of partners for each worker along the life-cycle is an impediment to produce precise estimates of their mean wages. ${ }^{19}$

An alternative strategy is to order workers locally (within the firm) exploiting monotonicity conditions from fully specified labor market models. For example, in the environment of Shimer and Smith [2000], wages are an increasing function of the worker type within the firm. This monotonicity condition provides a local ranking of workers under the assumption of correct specification of the model.

Unfortunately, variation in wages may be due to factors other than heterogeneity in worker types, even within the firm. First, workers who search on-the-job may achieve higher wages through new outside options (see, for example, Postel-Vinay and Robin [2002] and Cahuc, Postel-Vinay, and Robin [2006]). Second, firms may pay higher wages to some workers as a compensating differential for the kind of jobs or amenities they offer to them. Third, part of the variation in wages may be simply due to measurement error or match effects.

In this paper we exploit information contained in wages to rank workers. However,

\footnotetext{
${ }^{19}$ In our sample, workers have 1.3 employers on average along the 7-year duration of our panel. In a 30 year-long career, this would correspond to an average number of employers lower than 6 . Furthermore, when using data on the entire life-cycle of a worker, the assumption of time-invariant quality becomes more controversial.
} 
because of the aforementioned reasons, a worker ranking based on wage data is noisy, even within the firm. In what follows we show how we can consistently estimate the strength and the sign of sorting, in spite of the noise in the ranking of workers.

\section{The Strength of Sorting}

Our first contribution is to measure the strength of the association between firm and worker types. To illustrate our objective, consider two possible steady state distributions of matches $l_{1}(\varepsilon, p)$ and $l_{2}(\varepsilon, p)$, shown respectively in panels $(a)$ and $(c)$ of Figure 1 . Both distributions feature positive sorting. These distributions, however, differ in the strength of sorting $\eta$. The variance of employer types for a given worker is lower for $l_{1}(\varepsilon, p)$, so workers sort more intensively in panel (a) than in panel (c). Unfortunately, worker types are not observable. Thus, we must learn about the steady state distribution $l(\varepsilon, p)$ indirectly, from information from employer types and transitions.

We estimate the strength of sorting $\eta=\sqrt{\operatorname{var}[E[p \mid \varepsilon]] / \sigma_{p}^{2}}$ through information contained in observations of the same worker employed by different firms. Let $i$ denote a worker and $j$ an employer, so $\varepsilon_{i}$ is worker $i$ 's type and $p_{i j}$ is the type of the firm $j$ where $i$ is employed. Each draw from the steady state distribution of $i$ 's employers can be expressed as $p_{i j}=\phi_{i}+v_{i j}$, with $\phi_{i} \equiv E\left[p \mid \varepsilon_{i}\right]$ and $v_{i j}$ linearly independent of $\varepsilon_{i}$. The variance of $p$ can be decomposed into two components: $\operatorname{var}\left[p_{i j}\right]=\sigma_{p}^{2}=\sigma_{\phi}^{2}+\sigma_{v}^{2}$.

Therefore we can use standard panel data techniques to separate out permanent from transitory components in the variation of $p_{i j}$ (see for example Arellano [2003]). Take two random draws $p_{i j}$ and $p_{i h}$ from $\ell\left(\varepsilon_{i}, p\right)$ for each worker $i$ in a representative sample of workers. Then,

$$
E_{i}\left(p_{i j} p_{i h}\right)-E_{i}\left(p_{i j}\right) E_{i}\left(p_{i h}\right)=\operatorname{cov}\left(p_{i j}, p_{i h}\right)=\sigma_{\phi}^{2} .
$$

There is a large number of workers in our data set, but each has only a few partners. Thus, we can obtain precise estimates of $\sigma_{\phi}^{2}$ and $\sigma_{p}^{2}$ but not of the individual realization of $\phi_{i}$. The correlation coefficient between $p_{i j}$ and $p_{i h}$ is equal to the square of the correlation 
Figure 1: From Distribution of Matches to Distribution of Transitions

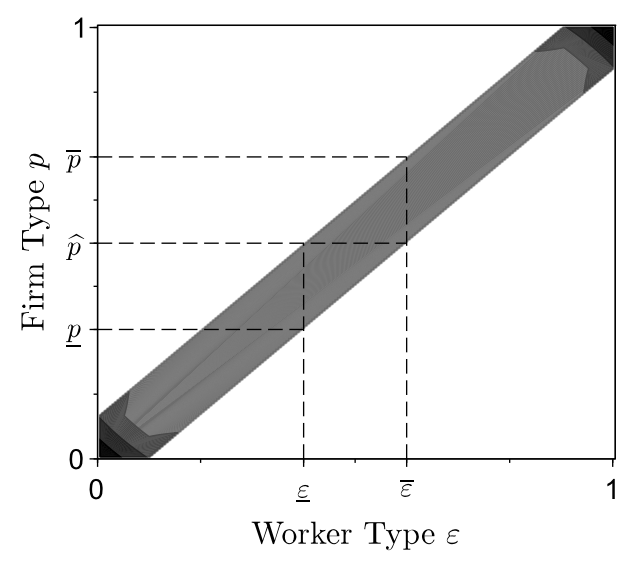

(a) Steady State Distribution $l_{1}(\varepsilon, p)$

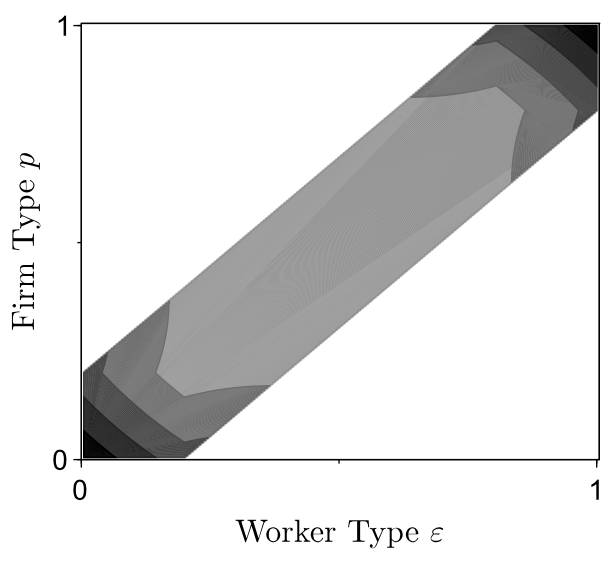

(c) Steady State Distribution $l_{2}(\varepsilon, p)$

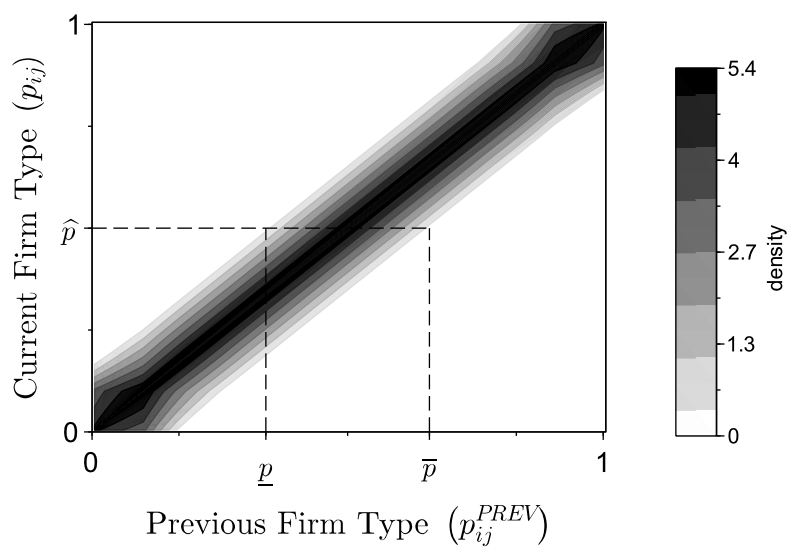

(b) Distribution of Transitions from $l_{1}(\varepsilon, p)$
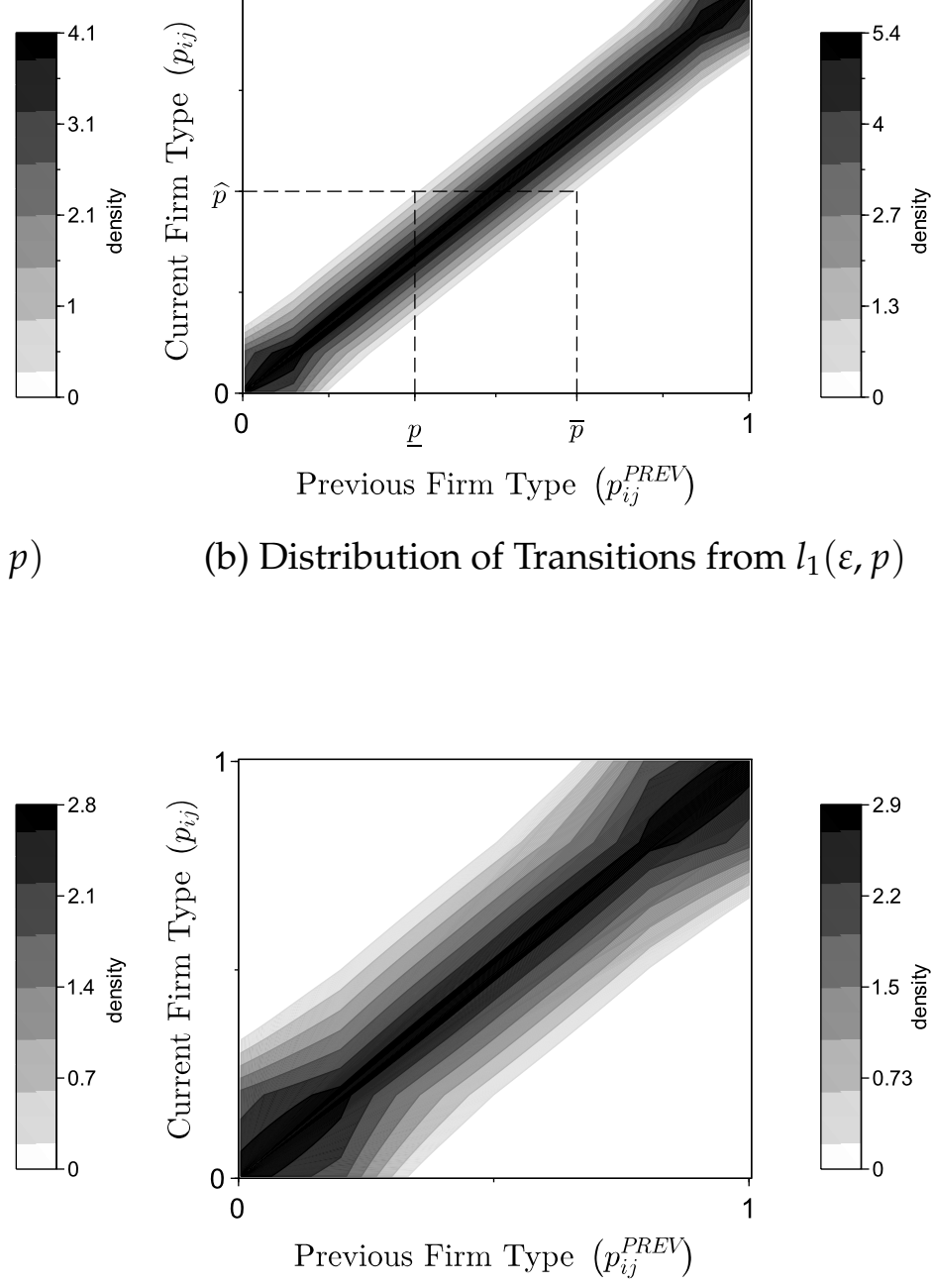

(d) Distribution of Transitions from $l_{2}(\varepsilon, p)$

ratio:

$$
\rho\left(p_{i j}, p_{i h}\right)=\frac{\operatorname{cov}\left(p_{i j}, p_{i h}\right)}{\operatorname{var}\left[p_{i j}\right]}=\frac{\sigma_{\phi}^{2}}{\sigma_{p}^{2}}=\eta^{2}
$$

We use transitions mediated by an unemployment spell to obtain employer draws. Take worker $i$, matched to an employer of type $p_{i j}$ after the unemployment spell. Let the employer type before unemployment be denoted by $p_{i j}^{P R E V}$. Since the transition is mediated by unemployment, $p_{i j}$ and $p_{i j}^{P R E V}$ are independent conditional on worker type $\varepsilon_{i}$. With exogenous job destruction and no on-the-job search, $p_{i j}$ and $p_{i j}^{P R E V}$ are random 
draws from the steady state distribution $\ell\left(p \mid \varepsilon_{i}\right){ }^{20}$

To illustrate the connection between the distribution of matches and the distribution of transitions, consider panels $(b)$ and $(d)$ in Figure 1, which depict the distribution of transitions corresponding to the distribution of matches from panels $(a)$ and $(c)$ respectively. Take for example the distribution of employees for firms of quality $\widehat{p}$ (those between $\underline{\varepsilon}$ and $\bar{\varepsilon})$ in panel $(a)$. Next, for each possible employee of $\hat{p}$, consider the distribution of potential employers (those between $p$ and $\bar{p}$ ). This operation induces a distribution of previous firms $p_{i j}^{P R E V}$ for each current firm $p_{i j}$. In this example, a current firm of quality $\hat{p}$ is associated to a distribution of previous firms of qualities between $\underline{p}$ and $\bar{p}$ - as shown in panel (b). The empirical distribution of transitions reveals the strength of sorting. Whenever the strength of sorting $\eta$ is higher - as in panel $(a)$, then also the correlation $\rho\left(p_{i j}^{P R E V}, p_{i j}\right)$ is higher - as in panel $(b)$.

We estimate the correlation ratio $\eta$ through $\rho\left(p_{i j}^{P R E V}, p_{i j}\right)$, using 178, 219 transitions mediated by an interim unemployment spell. Figure 2 presents the empirical distribution of all transitions. Previous firm type $p_{i j}^{P R E V}$ is on the $x$-axis while current firm type $p_{i j}$ is on the $y$-axis. It is noteworthy that the most current partner types are in the neighborhood of the previous firm type. The quality of the previous employer explains a significant fraction of the variation in current employer type. ${ }^{21}$

We report the estimates of $\eta=\sqrt{\rho\left(p_{i j}^{P R E V}, p_{i j}\right)}$ for different measures of sorting in Table 2. The estimated value for the correlation coefficient $\eta$ ranges between 0.51 and 0.53. Worker types explain more than a fourth of the variance in employer types. Different measures of profits lead to very close estimates of the strength of sorting. ${ }^{22}$

\footnotetext{
${ }^{20}$ With on-the-job search, two employers are still conditionally independent if there is an interim unemployment spell. However, the distribution of partners potentially depends not only on the worker type but also on the number of transitions after an unemployment spell (that is how much time the worker has climbed her ladder of employers). In Section 6.1 we allow for on-the-job search. In Sections 6.3 and 6.4 we acknowledge that job destruction may depend on the firm type and on the worker type, respectively. Our results are robust in all cases.

${ }^{21}$ Figure 2 also illustrates an useful fact. Let $S(p) \subset[0,1]$ be the set of workers accepted by a firm of type $p$. The sets $S(p)$ are intertwined. There is correlation between previous and current firm types. However, different quality firms are far from being in separated markets.

${ }^{22}$ This methodology can also be used to estimate the strength of sorting for specific subgroups in the population. Table 8 in Appendix A.2 reports the estimates of the strength of sorting $\eta$ by gender, blue or white collar, and different age groups. The estimates are in line with those in Table 2.
} 
Figure 2: Empirical Distribution of Transitions Mediated by Unemployment
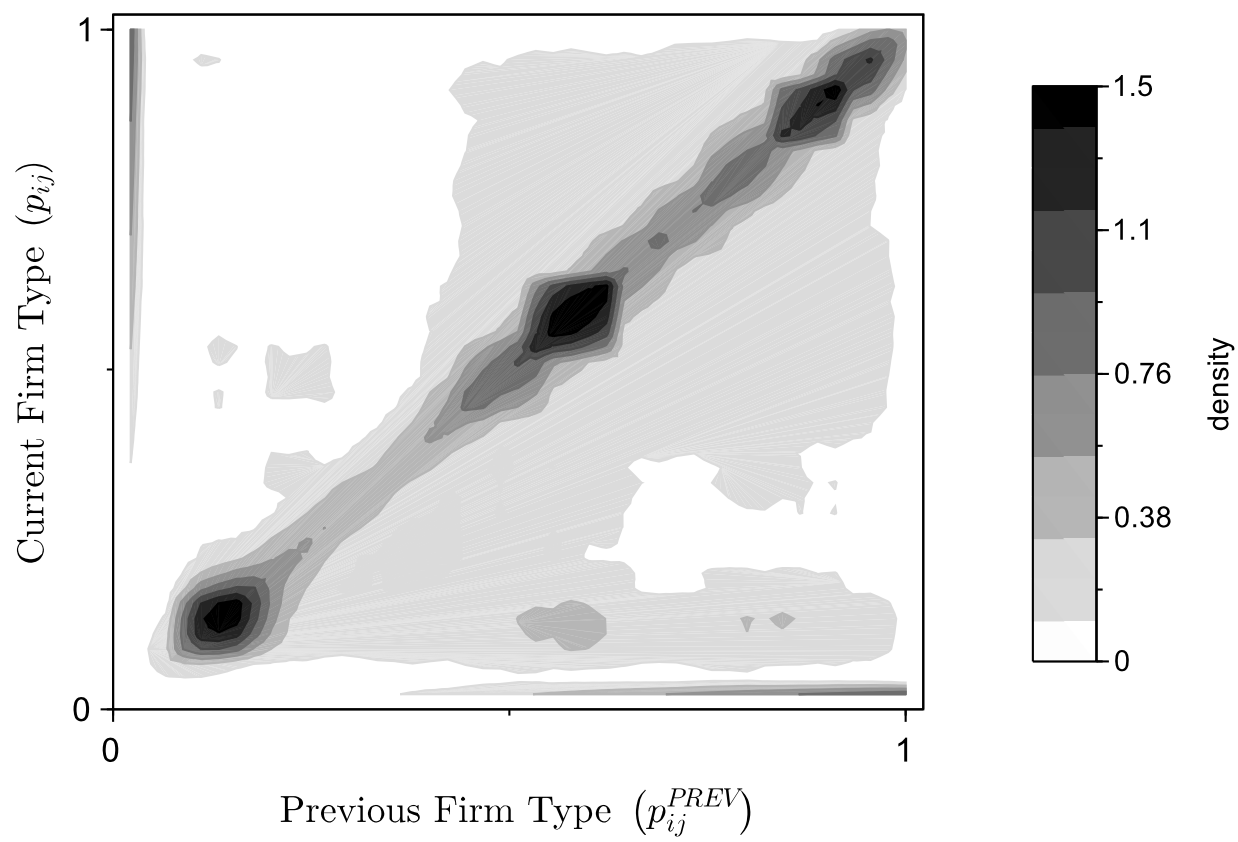

Bivariate kernel density estimate based on 178,219 transitions. Kernel type is Epanechnikov. Firms are ordered by economic profits per worker.

\section{The Sign of Sorting}

Our second contribution is to provide a consistent test for the sign of sorting. Each worker $i$ is matched to a number of employers, indexed by $j$. Employer types $p_{i j}$ are directly observable for each match. Were worker types $\varepsilon_{i}$ also directly observable, one could easily answer whether $E[p \mid \varepsilon]$ increases with $\varepsilon$. One could run a regression of the following

Table 2: Estimates of the strength of sorting $\eta$

\begin{tabular}{cc|cc|cc|c}
\multicolumn{2}{c|}{ Economic profits } & \multicolumn{2}{c|}{ GOS } & \multicolumn{2}{c|}{ AP } & \multirow{2}{*}{ ROE } \\
\cline { 1 - 5 } per worker & total & per worker & total & per worker & total & \\
\hline 0.526 & 0.520 & 0.527 & 0.523 & 0.510 & 0.530 & 0.523 \\
$(<0.001)$ & $(<0.001)$ & $(<0.001)$ & $(<0.001)$ & $(<0.001)$ & $(<0.001)$ & $(<0.001)$ \\
\hline
\end{tabular}

Number of observations is 178,219 . P-values in parentheses. 
form:

$$
p_{i j}=\alpha \varepsilon_{i}+v_{i j}
$$

and by recovering $\alpha$ from (2), learn about the sign of $\partial E[p \mid \varepsilon] / \partial \varepsilon$. Worker types are unobservable, so we must follow a different strategy to reveal the sign of sorting.

We build on the intuitive idea (as in Abowd et al. [1999] and Eeckhout and Kircher [2011]) that the better the worker, the better her labor market performance: expected wages $E[w \mid \varepsilon]$ should increase with worker type $\varepsilon$. Through observations of wages we obtain information on $E[w \mid \varepsilon]$ and so we learn indirectly about $\varepsilon$.

The monotonicity condition $\partial E[w \mid \varepsilon] / \partial \varepsilon>0$ would identify the sign of sorting if expected wages $E[w \mid \varepsilon]$ were observed. A regression of the form

$$
p_{i j}=\widehat{\gamma} E\left[w \mid \varepsilon_{i}\right]+\widehat{v}_{i j}
$$

would reveal the sign of $\alpha$ in equation (2), since sign $(\widehat{\gamma})=\operatorname{sign}(\alpha)$. Expected wages $E\left[w \mid \varepsilon_{i}\right]$ are not observed, but could in principle be estimated from data by the average wage of the worker $i$. The wage agent $i$ receives from her $j$ employer can always be expressed as

$$
w_{i j}=E\left[w \mid \varepsilon_{i}\right]+u_{i j}
$$

where $u_{i j}$ is linearly independent of $\varepsilon_{i}$. Therefore worker i's average wage is:

$$
\frac{1}{T_{i}} \sum_{T_{i}} w_{i j}=E\left[w \mid \varepsilon_{i}\right]+\frac{1}{T_{i}} \sum_{T_{i}} u_{i j}
$$

where $T_{i}$ is the number of employers of worker $i$. With a large number $T_{i}$ of draws from equation (4), $\lim _{T_{i} \rightarrow \infty} \frac{1}{T_{i}} \sum_{T_{i}} w_{i j}=E\left[w \mid \varepsilon_{i}\right]$. Unfortunately, workers have an average of 1.3 jobs along the 7 years of our panel. Moreover, both $p_{i j}$ and $w_{i j}$ are draws associated with the same firm $j$, so potentially $\operatorname{cov}\left(\widehat{v}_{i j}, u_{i j}\right) \neq 0$. For example, if better firms pay higher wages, then shocks $\widehat{v}_{i j}$ and $u_{i j}$ in equations (3) and (4) are (positively) correlated. Therefore, with $T_{i}$ small, the difference $\frac{1}{T_{i}} \sum_{T_{i}} u_{i j}$ between average observed wages and expected wages is correlated with $p_{i j}$. As a result, the variation in wages not coming from 
worker types does not behave as classical measurement error since it is endogenous in (3).

Equations (3) and (4) provide a framework to identify the sign of sorting. Take two independent draws $p_{i h}$ and $p_{i j}$ from the conditional distribution $\ell\left(\varepsilon_{i}, p\right)$. Then, wage $w_{i j}$ is correlated with the employer type $p_{i h}$ only through the worker type; that is cov $\left(\widehat{v}_{i h}, u_{i j}\right)=$ 0 . In such a case, $w_{i j}$ is a noisy measure of $E\left[w \mid \varepsilon_{i}\right]$ and we can treat $u_{i j}$ as classical measurement error to identify the sign of sorting.

We exploit transitions mediated by unemployment to obtain conditionally independent draws of wages and partner types. Take worker $i$, who after an unemployment spell obtains wage $w_{i j}$ in an employer of quality $p_{i j}$. Before being in unemployment, she was working for an employer of quality $p_{i j}^{P R E V}$, with wage $w_{i j}^{P R E V}$. Since the transition was mediated by unemployment, shocks $\widehat{v}_{i j}^{P R E V}$ and $u_{i j}^{P R E V}$ are independent of shocks $\widehat{v}_{i j}$ and $u_{i j}$, conditional on worker type $\varepsilon_{i}$. Moreover, previous jobs are draws from the steady state distribution of employers for each worker. ${ }^{23}$

The availability of transitions mediated by unemployment allows us to test directly whether better workers (higher $w_{i j}$ ) typically have better employers (higher $p_{i j}^{P R E V}$ ). The simplest way to test whether this occurs (on average) is to run

$$
p_{i j}^{P R E V}=\gamma w_{i j}+\widetilde{v}_{i j}
$$

Panel (A) of Table 3 reports estimates of $\gamma$ from equation (5) for different measures of profits. The sign is positive and significant for all measures of profits. Of course, since wages $w_{i j}$ are a noisy measure of worker types $\varepsilon_{i}$, then $\gamma \neq \widehat{\gamma}$. We argue how $\gamma$ provides an attenuated estimate of $\widehat{\gamma}$ (i.e. $|\gamma| \leq|\widehat{\gamma}|$ ) and therefore consistently informs us about the sign of sorting.

Two additional conditions are required to guarantee attenuation. First, the noise in the ranking of workers must be exogenous: $\operatorname{cov}\left(\widehat{v}_{i j}^{P R E V}, u_{i j}\right)=0$. Second, equation (2) must be linear and the noise in the measure of worker type in equation (4) must be ad-

\footnotetext{
${ }^{23}$ We maintain two simplifying assumptions through this section. First, we assume that match destruction is exogenous. This is not necessary, as we discuss in Sections 6.3 and 6.4. Second, when workers search on the job, wages after an unemployment spell are not necessarily random draws from the steady state distribution of wages. In Section 6.1 we relax this assumption.
} 
ditively separable. We focus on the second condition in Section 5.1. There, we present non-parametric results that impose less structure on the relationship between $p, \varepsilon$ and measurement error and also find strong evidence of positive sorting. In the remainder of this section we challenge the exogeneity assumption. First, we control for heterogeneity in workers not associated with the worker type that may lead to $\operatorname{cov}\left(\widehat{v}_{i j}^{P R E V}, u_{i j}\right) \neq 0$. Next, we also acknowledge that expected wages may rank workers only locally, for example when firms differ in the non-pecuniary retributions they offer. We rank workers locally (within the firm). Finally, we allow the sign of sorting to vary with the firm type. We find robust evidence of positive sorting under all these specifications.

Wages are determined by several factors that go beyond worker types. Female workers, migrants, and workers with lower tenure receive lower wages on average. Similarly, wages in different occupations vary, even for the same worker type. These sources of variation, which enter into $u_{i j}$, may also be associated to the (previous) firm type. For example, if female workers suffer segregation and wage discrimination, then firms of high quality hire fewer female workers and female workers make less money, leading to $\operatorname{cov}\left(\widehat{v}_{i j}^{P R E V}, u_{i j}\right)>0$.

We include observable characteristics $x_{i j}$ of both the worker and her job in equation (5) to prevent contamination from other sources of worker heterogeneity. Controls $x_{i j}$ include workers' age, age squared, tenure, tenure squared, time dummies and indicators for female, foreign-born, blue collar, white collar and managerial occupations. Panel (B) of Table 3 reports results with controls. The estimates of $\gamma$ are positive and significant for all measures of profits.

As discussed previously, $E[w \mid \varepsilon]$ does not necessarily order workers by their types. Workers care about wages but also about other characteristics of the job. Firms can differ in terms of their compensation packages: some may pay high wages with low level of amenities while others pay low wages with a high level of amenities. This source of firm heterogeneity is potentially correlated with the firm type and therefore may affect workers of different types unevenly. Moreover, some workers may compensate lower wages with lower unemployment risk. ${ }^{24}$ Even in Shimer and Smith's canonical model,

\footnotetext{
${ }^{24}$ In Appendix A.3 we present estimates of $\gamma$ controlling for individual specific unemployment risk.
} 
mean wages are non necessary monotone in the worker type (see Hagedorn et al. [2012] for a discussion).

We rank workers locally using within-firm variation in wages. By only comparing coworkers we first partial out between-firm heterogeneity in compensating differentials. Local rankings rely on expected wages being increasing in worker type only within the firm. ${ }^{25}$ Panel (C) of Table 3 reports the results including firm fixed effects in equation (5). Estimated $\gamma$ are positive and in most of the cases significant. Within-firm variation in wages is not only driven by the worker type. However the sign of $\gamma$ is still informative about the sign of sorting if there is attenuation. In this case, attenuation requires exogeneity of the within-firm variation of wages not driven by the worker type. In Panel (D) of Table 3 we present estimates of $\gamma$ including firm fixed effects and controlling for worker and job observable characteristics. The estimates of $\gamma$ are also positive and significant for all the measures of profits. ${ }^{26}$

We also study whether better workers $g o$ to better firms. We include observable characteristics $x_{i j}$ of both the worker and her job and run

$$
p_{i j}=\gamma w_{i j}^{P R E V}+x_{i j}^{\prime} \beta+\widetilde{v}_{i j}
$$

The estimates are positive and significant for all the measures of profits (see Panel (E) of Table 3$)^{2}{ }^{27}$

In our last set of results in Table 3, we allow for heterogeneity in $\gamma$ between firms of different quality $p$. In some labor markets positive sorting may occur for some range of quality $p$, and negative sorting for a different range. Our results from equation (5) with

\footnotetext{
${ }^{25}$ Although in models like Shimer and Smith [2000], $E[w \mid \varepsilon]$ is not necessarily monotone in the worker type, within-firm wages do order workers according to their types (see Lopes de Melo [2013]). In models with on-the-job search, renegotiation and endogenous search intensity as Lentz [2010], wages are not necessarily monotone in the worker type within the firm (see Bagger and Lentz [2014]). In Appendix A.4 we use a sub-sample of transitions where wages can be used to rank coworkers in Lentz [2010]'s environment. We also find evidence of positive assortative matching.

${ }^{26}$ In Appendix A.5 we present results using finer occupation categories. We use detailed information on workers' position in the contractual "job ladder" (livelli di inquadramento) to build a precise classification of jobs within the firm. The results including these more refined within-firm occupational controls strongly corroborate the existence of positive sorting.

${ }^{27}$ Firms' profits are affected by the quality of the workers they hire. We recompute firm $j$ 's profits as the longitudinal average profits over the years before worker $i$ gets hired. We rerun the estimation of equation (6), and also find positive and significant estimates.
} 
Table 3: Estimates of $\gamma$ (sign of sorting)

\begin{tabular}{|c|c|c|c|c|c|c|}
\hline \multicolumn{2}{|c|}{ Economic profits } & \multicolumn{2}{|c|}{ GOS } & \multicolumn{2}{|c|}{$\mathrm{AP}$} & \multirow[t]{2}{*}{$\mathrm{ROE}$} \\
\hline per worker & total & per worke & total & per worker & total & \\
\hline \multicolumn{7}{|c|}{ (A) - Estimates from equation (5) } \\
\hline 0.098 & 0.096 & 0.075 & 0.082 & 0.044 & 0.049 & 0.058 \\
\hline$(0.003)$ & $(0.003)$ & $(0.003)$ & $(0.003)$ & $(0.002)$ & $(0.003)$ & $(0.003)$ \\
\hline \multicolumn{7}{|c|}{ (B) - Estimates from equation (5) with Controls } \\
\hline 0.143 & 0.141 & 0.118 & 0.129 & 0.085 & 0.106 & 0.091 \\
\hline$(0.003)$ & $(0.003)$ & $(0.003)$ & $(0.003)$ & $(0.003)$ & $(0.004)$ & $(0.003)$ \\
\hline \multicolumn{7}{|c|}{ (C) - Estimates from equation (5) with Firm Fixed Effects } \\
\hline 0.025 & 0.031 & 0.019 & 0.023 & 0.001 & 0.001 & 0.004 \\
\hline$(0.003)$ & $(0.002)$ & $(0.003)$ & $(0.003)$ & $(0.003)$ & $(0.003)$ & $(0.003)$ \\
\hline \multicolumn{7}{|c|}{ (D) - Estimates from equation (5) with Firm Fixed Effects and Controls } \\
\hline 0.025 & 0.036 & 0.022 & 0.031 & 0.010 & 0.016 & 0.014 \\
\hline$(0.003)$ & $(0.004)$ & $(0.003)$ & $(0.004)$ & $(0.003)$ & $(0.004)$ & $(0.003)$ \\
\hline \multicolumn{7}{|c|}{ (E) - Estimates from equation (6) with Firm Fixed Effects and Controls } \\
\hline 0.020 & 0.016 & 0.016 & 0.014 & 0.012 & 0.009 & 0.012 \\
\hline$(0.003)$ & $(0.003)$ & $(0.003)$ & $(0.003)$ & $(0.003)$ & $(0.003)$ & $(0.003)$ \\
\hline \multicolumn{7}{|c|}{ (F) - Average $\left(\gamma_{j}\right)$ estimated from equation (7) at the Firm Level with Controls } \\
\hline 0.033 & 0.048 & 0.033 & 0.044 & 0.020 & 0.028 & 0.014 \\
\hline$(0.009)$ & $(0.010)$ & $(0.009)$ & $(0.010)$ & (0.009) & $(0.009)$ & (0.009) \\
\hline
\end{tabular}

Number of observations is 120,426 . Controls include worker's age, age squared, tenure, tenure squared, time dummies and indicators for females, foreign-born workers, blue collar, white collars and managerial occupations. Firm fixed-effects and time fixed-effects are included in Panels (C), (D) and (E). Standard errors in parentheses. 
firm fixed effects provide an estimate of the average effect of workers' local rankings on the expected ranking of the employer only if heterogeneity in $\gamma$ is i.i.d. We test for $\gamma$ at the firm-level by estimating

$$
p_{i j}^{P R E V}=\zeta_{j}+\gamma_{j} w_{i j}+x_{i j}^{\prime} \beta_{j}+\widetilde{v}_{i j}
$$

where $\zeta_{j}, \gamma_{j}$ and $\beta_{j}$ are firm-specific parameters, and $x_{i j}$ includes controls as before. Panel (F) of Table 3 reports the sample average of the estimated $\gamma_{j}$ at the firm level. The average $\gamma$ is also positive, and significant in most cases.

Finally, we report local estimates of $\gamma$. For any given firm $j$, the number of workers who land in $j$ after an unemployment spell is typically small, which makes the estimate of $\gamma$ for each firm unreliable. We therefore allow $\gamma$ to vary smoothly with firm type $p$. These results are valid under the assumption that firms of similar types have a similar $\gamma$. Figure 3 presents a Kernel non-parametric regression of the estimated $\gamma_{j}$ from equation (7) on the firm type. We find that better workers come from better firms for the whole support of new firms. ${ }^{28}$

\subsection{The Sign of Sorting: Non-Parametric Results}

Our test for the sign of sorting builds on a simple intuition: if there is positive sorting, a random draw from the steady state distribution of a better worker should be better on average than a random draw from the steady state distribution of a worse worker. We can test directly if this pairwise association exists in the data. We use the ranking of firms and the noisy ranking of workers to perform a Kendall test of association $(\tau)$.

Definition 3 (Kendall's $\tau$ ) Take any two rankings $a, b$. The Kendall rank correlation coefficient $\tau(a, b)$ between these rankings is given by

$$
\tau(a, b)=\frac{\sum_{n=1}^{N} \sum_{m<n} \mathbb{1}\left\{\left(a_{n}-a_{m}\right)\left(b_{n}-b_{m}\right)>0\right\}-\mathbb{1}\left\{\left(a_{n}-a_{m}\right)\left(b_{n}-b_{m}\right)<0\right\}}{\frac{1}{2} N(N-1)} .
$$

\footnotetext{
${ }^{28}$ As seen from Figure 2, and discussed in footnote 21, the sets of workers accepted by firms of different types are intertwined. Then, there is positive sorting in the economy.
} 
Figure 3: Local Estimates of $\gamma$ (sign of sorting)

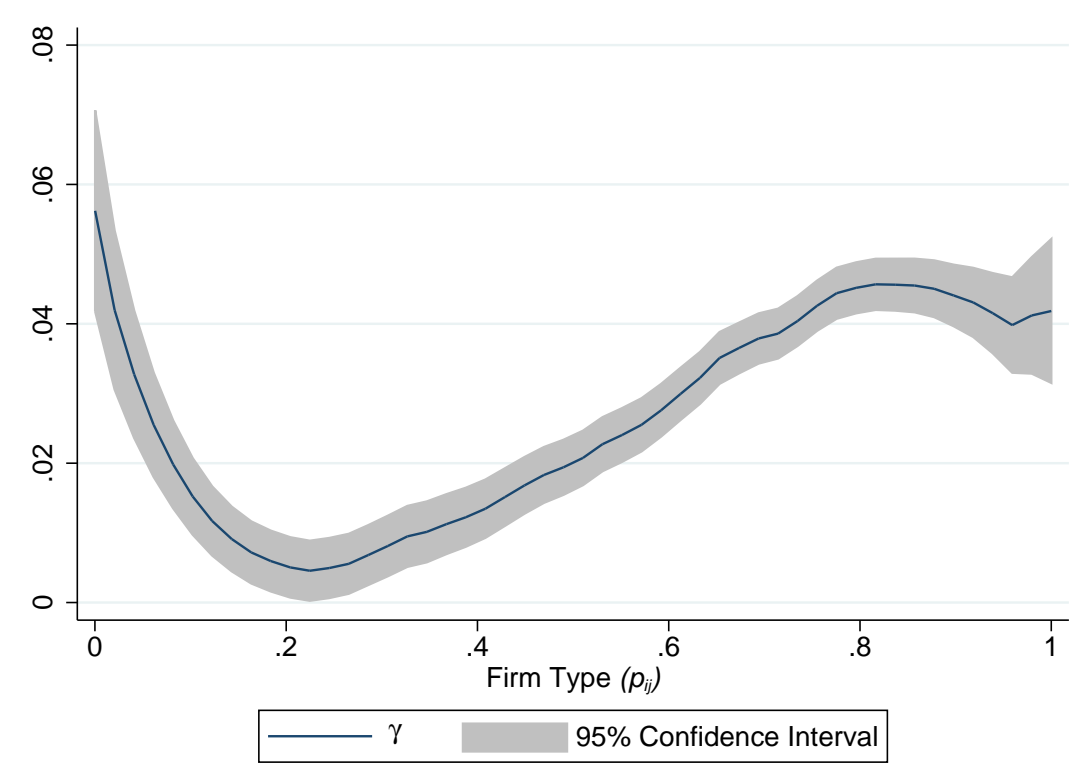

Kernel non parametric regression based on 120,426 observations. Kernel type is Epanechnikov. Firms are ordered by economic profits per worker.

We present results using Kendall's $\tau$ for two reasons. First, Kendall's $\tau$ provides a non-parametric measure of the association between two variables. Second, we can consistently estimate the sign of the association using a Kendall's $\tau$ under mild conditions in the specification of the noise in the ranking of workers.

As discussed before, there may be variation in wages not explained by worker types, even within the firm. On-the-job search and renegotiation (as in Postel-Vinay and Robin [2002] and Cahuc et al. [2006]), measurement error, or match effects may generate this. We relax the specification of wages as follows. Assume that wages (or a monotone increasing transformation $\psi_{1}$ of wages) are given by

$$
\psi_{1}\left(w_{i j}\right)=\psi_{2}\left(\varepsilon_{i}\right)+u_{i j},
$$

where $\psi_{2}$ is strictly increasing and $u_{i j}$ is an i.i.d. shock. Equation (8) is satisfied in the case of classical measurement error, or i.i.d. match effects in any monotone transformation of wages, such as the standard assumption of classical error in log-wages. Moreover, if we only compare coworkers, equation (8) holds if wages are renegotiated as in Postel-Vinay 
and Robin [2002] or as in Cahuc et al. [2006]. ${ }^{29}$

Similarly, assume that employers are drawn from

$$
\psi_{3}\left(p_{i j}\right)=\alpha \psi_{4}\left(\varepsilon_{i}\right)+v_{i j}
$$

where $\psi_{3}(\cdot)$ and $\psi_{4}(\cdot)$ are strictly increasing functions and $v_{i j}$ is i.i.d. The sign of $\tau(p, \varepsilon)$ is determined by the sign of $\alpha$. Unfortunately, since $\varepsilon$ is unobserved, we cannot recover $\tau(p, \varepsilon)$ directly. However we can learn about on the sign of $\tau(p, \varepsilon)$ estimating $\tau(p, w)$. With noisy rankings of workers, the Kendall's correlation between worker and firm types is attenuated. Attenuation increases the probability of accepting the null of no sorting when the true correlation is different from zero. The higher the informational content about worker types conveyed by wages, the higher the power of our test on the sign of sorting. Moreover, our result extends to the case of rank correlation: the (Spearman) rank correlation $\rho$ is always larger than the Kendall coefficient $\tau$. Thus, $\tau(p, w)$ provides a consistent test for the sign of sorting. Lemma 1 presents this formally.

Lemma 1 Assume that workers' wages and employers are drawn from (8) and (9). Then,

1. $\operatorname{sign}(\tau(p, w))=\operatorname{sign}(\tau(p, \varepsilon))=\operatorname{sign}(\alpha)$ and

2. $|\tau(p, w)| \leq|\tau(p, \varepsilon)| \leq|\rho(p, \varepsilon)|$.

See Appendix A.6 for the proof.

Table 4 presents estimates of Kendall's $\tau(p, w)$. We first present results constructing all possible pairs in the data, and ordering workers in terms of wages. Second, we control non-parametrically for observable characteristics by comparing workers in the same group in terms of gender and occupation. Third, we only compare coworkers measuring the association at the firm level. In this last case we report the sample average of firmspecific Kendall's correlations. Results using aggregated profits and profit per worker are reported in Columns (1) and (2) respectively. We find that the association is positive and significant in all cases.

\footnotetext{
${ }^{29}$ See Equation (3) in Cahuc et al. [2006] and equation (5) in Postel-Vinay and Robin [2002]. In PostelVinay and Robin [2002], $\psi_{1}$ is a log transformation.
} 
Table 4: Estimates of Kendall's Coefficient $\tau$ of Association between Previous Firm and Wages

\begin{tabular}{|c|c|c|c|}
\hline Sample & Observations & (1) Total Profits & (2) Profit Per Worker \\
\hline All Workers & 119,772 & $\begin{array}{c}0.087 \\
(<0.001)\end{array}$ & $\begin{array}{c}0.076 \\
(<0.001)\end{array}$ \\
\hline Blue-Collar Male & 66,899 & $\begin{array}{c}0.067 \\
(<0.001)\end{array}$ & $\begin{array}{c}0.061 \\
(<0.001)\end{array}$ \\
\hline White-Collar Male & 20,201 & $\begin{array}{c}0.071 \\
(<0.001)\end{array}$ & $\begin{array}{c}0.0 \\
(<0.001)\end{array}$ \\
\hline Blue-Collar Female & 20,207 & $\begin{array}{c}0.178 \\
(<0.001)\end{array}$ & $\begin{array}{c}0.146 \\
(<0.001)\end{array}$ \\
\hline White-Collar Female & 12,415 & $\begin{array}{c}0.128 \\
(<0.001) \\
\end{array}$ & $\begin{array}{c}0.083 \\
(<0.001) \\
\end{array}$ \\
\hline Firm by Firm Average & 119,772 & $\begin{array}{c}0.018 \\
(<0.001)\end{array}$ & $\begin{array}{c}0.022 \\
(<0.001)\end{array}$ \\
\hline
\end{tabular}

In column (1) firms are ranked in terms of total economic profits. In column (2) firms are ranked in terms of economic profits per worker. Each row represents a sample where $\tau$ is estimated. P-values in parentheses.

\section{Robustness Checks}

Our identification strategy relies on the availability of random draws from the steady state distribution of partners and wages. We focus on matches mediated by an unemployment spell to guarantee independence. If workers search on-the job, partners' types and wages after an unemployment spell are not necessarily random draws from steady state. In Section 6.1, we present evidence suggesting that this concern does not drive our results. Moreover, information spillovers from former coworkers may generate correlation between employer types, even conditioning by worker type. In Section 6.2, we challenge our assumption of conditional independence between two subsequent partners.

We have maintained the simplifying assumption that job destruction is only exogenous. This is a common assumption in models describing the labor market and allows us to interpret firm types before unemployment as random draws from the steady state distribution of partners. However, some firms may be more likely to layoff workers than others. Similarly, some workers may be more likely to be fired than others. These potential 
sources of selection bias are analyzed and discarded in Sections 6.3 and 6.4 respectively. ${ }^{30}$

\subsection{Identification of Sorting with On-the-Job Search}

We take advantage of the longitudinal dimension of our data set to make inference on the strength and sign of sorting when draws out of unemployment are not necessarily from steady state. Intuitively, workers may be less selective from unemployment if they can continue to search while on the job. Over time workers change jobs, and eventually the effect of the unemployment spell fades away. ${ }^{31}$ Let $p_{i, t}$ be the type of the employer $t$ periods after the beginning of the unemployment spell. As $t$ grows, the distribution of employers converges to the steady state distribution.

We measure the strength of sorting $\eta$ through the correlation of independent draws of employer types. Let $p_{i}^{P R E V}$ denote the employer type before unemployment. The correlation $\eta_{t}^{2} \equiv \operatorname{cov}\left(p_{i}^{P R E V}, p_{i, t}\right) / \sigma_{p}^{2}$ converges to the correlation between two independent draws from the steady state distribution as $t$ grows. Panels (A) and (B) in Figure 4 present estimates of $\eta_{t}^{2}$ over time. For low values of $t$ the correlation $\eta_{t}^{2}$ increases as $t$ grows. However, after approximately a year $\eta_{t}^{2}$ becomes stable around the values from Section 4. The fact that $\eta_{t}^{2}$ is low when $t$ is small suggests that after an unemployment spell, workers are less discriminating in terms of which firms they accept, and therefore there is weaker sorting.

We follow a similar line of reasoning to identify the sign of sorting. We study whether better workers move to better firms (as in Panel (E) of Table 3). We focus on the correlation $\gamma_{t}$ between wages $w_{i}^{P R E V}$ before unemployment and the type $p_{i, t}$ of the employer $t$ periods after the unemployment spell starts. The correlation $\gamma_{t}$ converges to the correlation between random draws from the steady state distribution of wages and partner types as $t$ grows. Panels (C) and (D) in Figure 4 present estimates of $\gamma_{t}$. The sign of sorting is always positive (and $\gamma_{t}$ is significantly different from zero for all $t$ except for $t=12$, with firms ordered by average profits).

\footnotetext{
${ }^{30}$ For all robustness checks we order firms by economic profits (aggregated and per-worker). Results using different measures of profits do not differ significantly.

${ }^{31}$ When the process that drives transitions (both in and out of unemployment, and job-to-job) is ergodic, the distribution of partners converges to its steady state.
} 
Figure 4: Convergence of $\eta_{t}^{2}$ and $\gamma_{t}$

$\mathrm{A}: \stackrel{2}{t^{2}}$

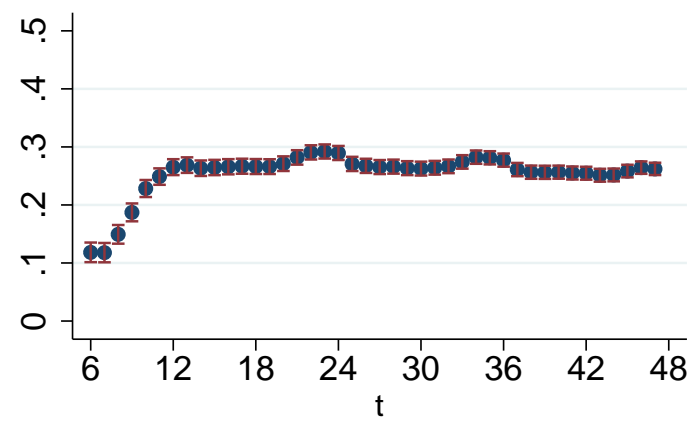

C: $t$

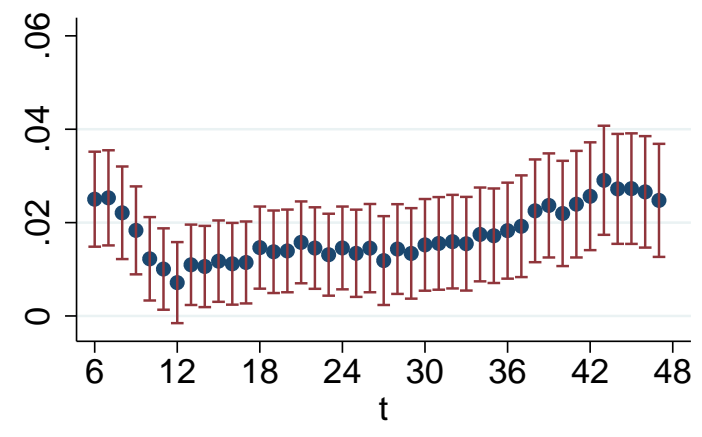

$\mathrm{B}:{ }_{t}^{2}$

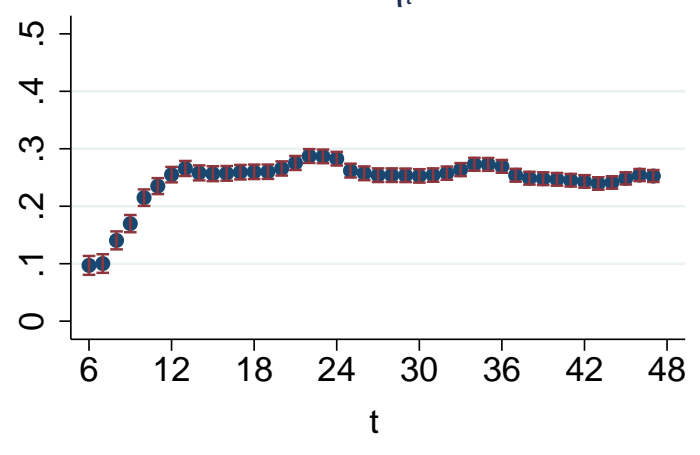

D: $t$

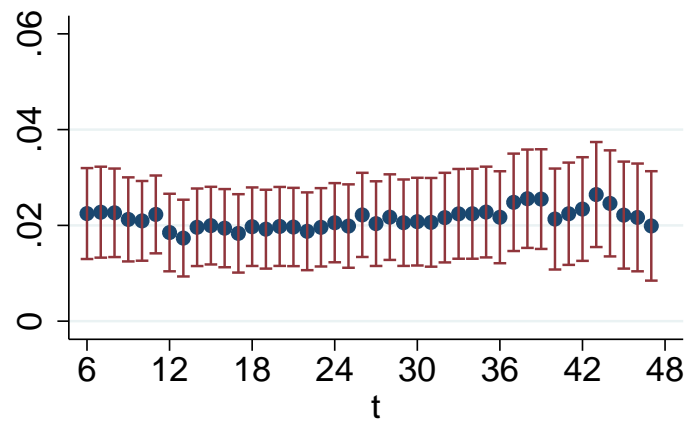

Panels (A) and (B) present estimates of $\eta_{t}^{2}$ for $t$ ranging between 6 and 48 . Panels (C) and (D) present estimates of $\gamma_{t}$ for $t$ ranging between 6 and 48. Red bars indicate $95 \%$ confidence intervals. We rank firms in terms of average profit in Panels (A) and $(C)$. We rank firms in terms of average profit per worker in Panels (B) and (D). For each $t, \eta_{t}$ and $\gamma_{t}$ are estimated on a sample of workers that are observed at least for 48 months after an unemployment spell.

\subsection{Serially Correlated Transitory Component in Employer's type}

Employers' types before and after an unemployment spell are not necessarily independent. Workers may find new jobs exploiting networks of former fellow workers (see Cingano and Rosolia [2012]). Then, employer types before and after an unemployment spell may be correlated, even conditioning on worker type. We challenge our assumption of conditional independence allowing for a serially correlated transitory component in the variation of employer types. Let worker i's employer type be given by

$$
p_{i j}=\phi_{i}+\omega_{i j}
$$


where $\omega_{i j}=\zeta \omega_{i, j-1}+v_{i j}$ and $v_{i t}$ is white noise.

We use information on individuals with at least two transitions. If only two partners are observed, unobserved heterogeneity $\left(\sigma_{\phi}\right)$ and individual dynamics $\zeta$ cannot be distinguished (see Arellano [2003]). The model is just identified for those workers for whom we observe three partners. We use standard panel data techniques to analyze the covariance structure of models with dynamic error components. Consider a sample of workers observed in three consecutive jobs. We observe employer types $\left(p_{i j}^{P R E V}, p_{i j}, p_{i j}^{P O S T}\right)$. As described in Arellano [2003], a model with a heterogeneous permanent component and an $\mathrm{AR}(1)$ transitory component is summarized by the three following variance restrictions:

$$
\begin{gathered}
\operatorname{var}\left(p_{i j}^{P R E V}\right)=\operatorname{var}\left(p_{i j}\right)=\operatorname{var}\left(p_{i j}^{P O S T}\right)=\sigma_{\phi}^{2}+\sigma_{\omega}^{2} \\
\operatorname{cov}\left(p_{i j}^{P R E V}, p_{i j}\right)=\operatorname{cov}\left(p_{i j}, p_{i j}^{P O S T}\right)=\sigma_{\phi}^{2}+\zeta \sigma_{\omega}^{2} \\
\operatorname{cov}\left(p_{i j}^{P R E V}, p_{i j}^{P O S T}\right)=\sigma_{\phi}^{2}+\zeta^{2} \sigma_{\omega}^{2}
\end{gathered}
$$

We can recover $\sigma_{\phi}^{2} \zeta$ and $\sigma_{v}^{2}$ from the variance of partners, the covariance between the current partner and previous partner, and the covariance between the previous partner and the next partner. Therefore we can construct $\eta=\sqrt{\frac{\sigma_{\phi}^{2}}{\sigma_{\phi}^{2}+\sigma_{v}^{2}}}$.

Columns (1) and (2) of Table 5 present our results. Estimated $\eta$ are slightly larger than those presented in Table 2. The estimated $\zeta$ suggests that the serial correlation in the transitory component in partner's types is weak but significantly different than zero. Since we allow for serial correlation in the transitory component of the employer type, we can also exploit information contained in job-to-job transitions. Estimates of the strength of sorting including job-to-job transitions are presented in columns (3) and (4) of Table 5, and are in line with those presented in Table 2.

\subsection{Selection of Firms}

We next show that job destruction is associated with firm type, incorporate this in our estimates of the strength and sign of sorting, and show that results do not change sig- 
Table 5: Estimates of strength of sorting $\eta$ with serially correlated transitory component in partner types

\begin{tabular}{c|cc|cc}
\multirow{4}{*}{} & \multicolumn{2}{|c|}{ Excluding Job-to-Job Transitions } & \multicolumn{2}{c}{ Including Job-to-Job Transitions } \\
\cline { 2 - 5 } & $\begin{array}{c}\text { Economic profits } \\
\text { per worker }(1)\end{array}$ & $\begin{array}{c}\text { Economic profits } \\
\text { total (2) }\end{array}$ & $\begin{array}{c}\text { Economic profits } \\
\text { per worker (3) }\end{array}$ & $\begin{array}{c}\text { Economic profits } \\
\text { total (4) }\end{array}$ \\
\hline$\eta$ & 0.623 & 0.614 & 0.563 & 0.588 \\
$\zeta$ & $(<0.001)$ & $(<0.001)$ & $(<0.001)$ & $(<0.001)$ \\
& 0.054 & 0.052 & 0.025 & 0.005 \\
& $(<0.001)$ & $(<0.001)$ & $(0.002)$ & $(0.475)$ \\
\hline
\end{tabular}

Number of individuals in columns (1) and (2) is 20,747. Number of individuals in columns (3) and (4) is 28,223 . P-values - in parentheses - are obtained by bootstrap based on 1,000 re-samples. Bootstrap samples from the pool of workers.

nificantly. Firms that are more likely to layoff workers appear more often as previous employers in a sample of workers who transit unemployment. Our identification strategy relies on observing random draws from the steady state distribution of partners, so we must account for the over-representation of firms with higher destruction rates.

We calculate the monthly firm-specific destruction rate as the fraction of employees observed in unemployment in the following month. Although firm-specific destruction rates are significantly heterogeneous, we find a clear pattern between destruction rates and firm type. Figure 5 presents a non-parametric regression of the firm-specific destruction rate on the firm type. Firms of worse types are more likely to layoff workers than those of higher types.

Table 6 shows estimates of the strength $(\eta)$ and sign $(\gamma)$ of sorting weighting each observation by the inverse of the destruction rate corresponding to the previous employer. The estimated strength of sorting $\eta$ is similar to that reported in Section 4 (the range of $\eta$ in Table 6 is between 0.49 and 0.54 , compared to a range between 0.51 and 0.53 in Table 2). The sign of sorting $\gamma$ is positive and significant in all specifications.

\subsection{Selection of Workers}

Workers who are laid off are potentially different from those who do not transit unemployment. Our results are consistent for the group of workers who transit unemployment. 
Figure 5: Destruction Rate by Firm Type

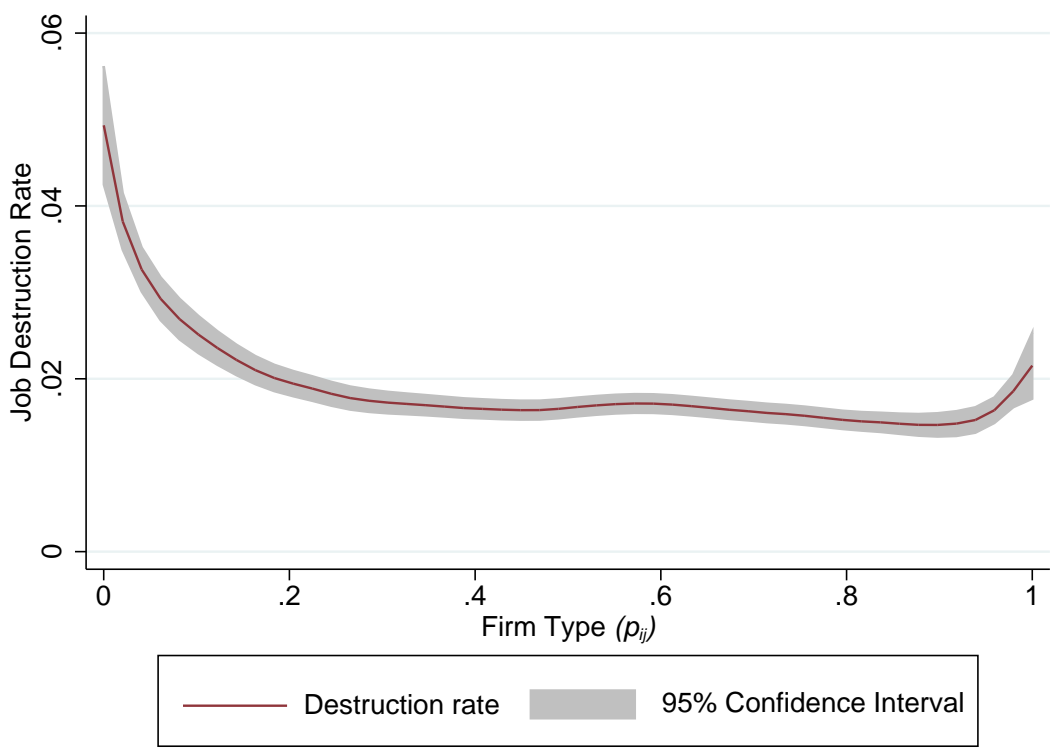

Kernel non parametric regression based on 178,219 observations. Kernel type is Epanechnikov. Firms are ordered by economic profits per worker.

Table 6: Strength $\eta$ and Sign $\gamma$ of Sorting, Weighted by Firm-specific Destruction Rates

\begin{tabular}{l|lc|lc} 
& \multicolumn{2}{|l|}{ Economic Profits per worker } & \multicolumn{2}{l}{ Total Economic Profits } \\
\hline$\eta$ & 0.491 & $(<0.001)$ & 0.536 & $(<0.001)$ \\
$\gamma$ & 0.033 & $(0.009)$ & 0.058 & $(0.008)$ \\
\hline
\end{tabular}

Observations are weighted by the inverse of the destruction rate estimated for each firm. There are 178, 219 observations for the estimation of the strength of sorting $\eta$. There are 120,426 observations for the estimation of the sign of sorting $\gamma$. P-values in parentheses.

However, that group is a non-random sample of workers. Their sorting pattern may be different from that of other workers.

We consider firms that layoff their complete workforce. In this case, all workers are forced to leave the firm, irrespective of their characteristics. ${ }^{32}$ In our data it is possible to identify 710 firms that closed their business during the 1995-2001 time period, involving 15,255 workers. We obtain estimates of the sign and strength of sorting for this subsample (see Table 7). Despite this dramatic reduction in sample size, the results are once again

\footnotetext{
${ }^{32}$ Cingano and Rosolia [2012] use a similar strategy to identify the strength of information spillovers on workers' unemployment duration.
} 
Table 7: Strength $\eta$ and Sign $\gamma$ of Sorting Estimated from Firm Closures

\begin{tabular}{c|lc|lc} 
& \multicolumn{2}{|l|}{ Economic Profits per worker } & \multicolumn{2}{|c}{ Total Economic Profits } \\
\hline$\eta$ & 0.496 & $(<0.001)$ & 0.478 & $(<0.001)$ \\
$\gamma$ & 0.016 & $(0.009)$ & 0.017 & $(0.008)$ \\
\hline
\end{tabular}

Number of observations is 15,255 . $\gamma$ is the coefficient of a regression of the new employer's firm type on the worker's wage percentile in the current firm. The regression used to obtain $\gamma$ includes controls for worker's age, age squared, tenure, tenure squared, time dummies and indicators for females, foreign-born workers, blue collar, white collars and managerial occupations. Firm fixed-effects and time fixed-effects are also included. P-values in parentheses.

indicative of positive sorting, with a similar strength to that of our baseline analysis. We find $\eta$ close to $50 \%$ and $\gamma$ positive and statistically significant.

\section{Conclusion}

We present a new methodology to identify both the strength and the sign of sorting in the labor market. Our methodology exploits information not only from workers' mobility and wages, but also from firms' profits. We apply our approach to a panel data set that combines social security earnings records for workers in the Veneto region of Italy with detailed financial data for firms.

We rank firms by their profits. Previous literature has focused on using information on wages alone to try to identify sorting. Profits have two main advantages with respect to wages. First, firms aim to maximize profits, whereas workers also care about job characteristics other than wages. Non-pecuniary compensation then makes wages a noisy measure of a worker's underlying quality. Second, firms are matched to a large number of workers, whereas workers only have a few employers in their work history. As a result, firms' profits integrate out match-specific noise, but workers' wages do not.

Our tests exploit the information contained in profits to uncover the pattern of sorting. This information, readily available in several data sets, complements the information on transitions and wages typically used to test for sorting. Without relying on one specific model of the labor market, we show how to identify the strength and sign of sorting. 
In our first contribution, we propose a methodology to measure the strength of sorting that does not require a ranking of workers (and thus does not require using wages). We characterize the strength of sorting by the correlation ratio, which measures the fraction of the variance in firm types explained by worker types. We exploit information contained in transitions and with standard panel data techniques separate the within worker variation of partners from the between worker variation. We find that worker types explain about $27 \%$ of the total variance, which corresponds to a correlation ratio of about $52 \%$.

In our second contribution, we present a test for the sign of sorting. We use information contained in wages to rank workers. However, variation in wages is driven by several factors other than worker types. Thus, wages are a noisy measure of the type of the worker. The potential non-classical nature of the noise represents a major threat to obtaining a consistent test. We use independent draws from a worker's distribution of employers to guarantee that the noise in wages is uncorrelated with the worker and firm types. In this case, we obtain an attenuated estimate of the correlation between worker and firm types. The attenuation of the point estimate is not detrimental, as we only need to establish its sign. Therefore, we can consistently estimate the sign of sorting despite the noise in the ranking of workers.

Intuitively, we test whether better workers (as indicated by their wages in their employer after unemployment) are typically employed by better firms (as indicated by the firm type before unemployment). In this way, the noise in wages is independent of the previous employer type. Furthermore, we provide additional checks to guarantee attenuation. We first partial out between-firm heterogeneity by comparing coworkers. We also restrict wage variation to observationally equivalent workers. Moreover, we estimate the direction of sorting non-parametrically through Kendall's rank correlations. We find robust evidence of positive sorting.

We provide several robustness checks for our results. We construct several alternative measures of profits and show that the results are similar across these measures. For our main results, we consider transitions mediated by unemployment and take job destruction as exogenous. We account for selection in both dimensions and show that our results do not change significantly. 
Our tests for the strength and sign of sorting are easy to perform, and rely on data that is either available for several countries and regions, or can be constructed from available sources. Although beyond the scope of this paper, these characteristics make our tests feasible for the comparison of different labor markets.

\section{References}

Abowd, J. M., F. Kramarz, P. Lengerman, and S. Perez-Duarte (2004): “Are Good Workers Employed by Good Firms? A Test of a Simple Assortative Matching Model for France and the United States," Working Paper.

Abowd, J. M., F. Kramarz, and D. N. Margolis (1999): “High Wage Workers and High Wage Firms," Econometrica, 67, 251-334.

Andrews, M. J., L. GILL, T. SCHANK, AND R. Upward (2008): “High wage workers and low wage firms: negative assortative matching or limited mobility bias?" Journal of the Royal Statistical Society: Series A (Statistics in Society), 171, 673-697.

ARACHI, G. AND F. BIAGI (2005): “Taxation, Cost of Capital and Investment: Do Tax Asymmetries Matter?" Giornale degli Economisti, 64, 295-322.

Arellano, M. (2003): “Panel data econometrics," OUP Catalogue.

AtAKAn, A. E. (2006): "Assortative Matching with Explicit Search Costs," Econometrica, $74,667-680$.

BAgGeR, J. AND R. Lentz (2014): “An Empirical Model of Wage Dispersion with Sorting," Working Paper.

BANCA D’ITAlia (2002): “Relazione annuale sul 2002,” Roma.

Bartolucci, C. (2013): “Gender Wage Gaps Reconsidered: A Structural Approach Using Matched Employer-Employee Data," Journal of Human Resources, 48, 998-1034. 
BARTOlucci, C. AND I. Monzón (2014): “Frictions Lead to Sorting: a Partnership Model with On-the-Match Search," Working Paper.

BECKeR, G. S. (1973): “A Theory of Marriage: Part I," Journal of Political Economy, 81, $813-46$.

Bloom, N., M. Schankerman, And J. VAn Reenen (2013): “Identifying Technology Spillovers and Product Market Rivalry," Econometrica, 81, 1347-1393.

Bloom, N. And J. VAn ReEnen (2007): “Measuring and Explaining Management Practices Across Firms and Countries," The Quarterly Journal of Economics, 122, 1351-1408.

Caballero, R. J. And M. L. Hammour (1994): “The Cleansing Effect of Recessions," American Economic Review, 84, 1350-68.

Cahuc, P., F. Postel-VinaY, AND J.-M. Robin (2006): "Wage Bargaining with On-theJob Search: Theory and Evidence," Econometrica, 74, 323-364.

CAPÉRAÀ, P. AND C. GENEST (1993): “Spearman's is larger than kendall's for positively dependent random variables," Journal of Nonparametric Statistics, 2, 183-194.

Card, D., F. Devicienti, AND A. Maida (2014): “Rent-sharing, Holdup, and Wages: Evidence from Matched Panel Data," Review of Economic Studies, 81, 84-111.

CARD, D., J. Heining, AND P. KLINE (2013): “Workplace Heterogeneity and the Rise of West German Wage Inequality," The Quarterly Journal of Economics, 128, 967-1015.

CASADIO, P. (2004): "Wage Formation in the Italian Private Sector After the 1992-93 Income Policy Agreements," in Institutions and Wage Formation in the New Europe, ed. by G. Fagan, F. P. Mongelli, and J. Morgan, Elgar, Edward Publishing, Inc, 112-133.

CHADE, H. (2006): "Matching with noise and the acceptance curse," Journal of Economic Theory, 129, $81-113$.

Cingano, F. AND A. Rosolia (2012): "People I know: job search and social networks," Journal of Labor Economics, 30, 291-332. 
Collard-Wexler, A. (2013): “Demand Fluctuations in the Ready-Mix Concrete Industry," Econometrica, 81, 1003-1037.

CONTINI, B. AND U. TRIVELlato (2005): Eppur si muove: Dinamiche e persistenze nel mercato del lavoro italiano, Bologna: Il Mulino.

DELL' ARINGA, C. AND C. LUCIFORA (1994): “Collective bargaining and relative earnings in Italy," European Journal of Political Economy, 10, 727-747.

Dupuy, A. AND A. GALiCHON (2014): "Personality Traits and the Marriage Market," Journal of Political Economy, 122, $1271-1319$.

EecKHout, J. AND P. KIRCHER (2010): "Sorting and decentralized price competition," Econometrica, 78, 539-574.

(2011): "Identifying sorting - in theory," The Review of Economic Studies, 78, 872906.

— (2012): “Assortative matching with large firms: Span of control over more versus better workers," Working Paper.

Elston, J. A. AND L. Rondi (2006): "Shareholder Protection and the Cost of Capital Empirical Evidence from German and Italian Firms," CERIS Working Paper 8, Institute for Economic Research on Firms and Growth - Moncalieri (TO).

FrANZOSI, A. (2008): “Costo del Capitale e Struttura Finanziaria: Valutazione degli Effetti di IRAP e DIT," Working Paper, Instituto per la Ricerca Sociale (Milano).

Garicano, L. AND P. HeAton (2010): “Information Technology, Organization, and Productivity in the Public Sector: Evidence from Police Departments," Journal of Labor Economics, 28, 167-201.

Gautier, P. A. And C. N. Teulings (2006): "How large are search frictions?" Journal of the European Economic Association, 4, 1193-1225.

Hagedorn, M., T. H. LAW, AND I. MANOvSKII (2012): “Identifying Sorting,” Working Paper. 
Hause, J. C. (1980): “The Fine Structure of Earnings and the On-the-Job Training Hypothesis," Econometrica, 48, 1013-29.

ICHNIOWSKI, C. AND K. L. SHAW (2003): “Beyond Incentive Pay: Insiders' Estimates of the Value of Complementary Human Resource Management Practices," The Journal of Economic Perspectives, 17, 155-180.

ISTAT (2000): “La flessibilità del mercato del lavoro nel periodo 1995-96," ISTAT, Informazioni, 34 .

KRUSKAL, W. H. (1958): “Ordinal Measures of Association," Journal of the American Statistical Association, 53, pp. 814-861.

LazeAr, E. P. AND K. L. SHAW (2009): “Wage Structure, Raises and Mobility: An Introduction to International Comparisons of the Structure of Wages Within and Across Firms," in The Structure of Wages: An International Comparison, National Bureau of Economic Research, Inc, NBER Chapters, 1-57.

LENTZ, R. (2010): “Sorting by search intensity," Journal of Economic Theory, 145, 1436 1452.

Lillard, L. A. AND Y. Weiss (1979): “Components of Variation in Panel Earnings Data: American Scientists, 1960-70," Econometrica, 47, 437-54.

Lindenlaub, I. (2014): "Sorting Multidimensional Types: Theory and Application," Working Paper.

Lise, J., C. MEghIR, AND J.-M. Robin (2013): “Matching, sorting and wages,” Working Paper.

LOPES De Melo, R. (2013): “Firm Wage Differentials and Labor Market Sorting: Reconciling Theory and Evidence," Working Paper.

Meghir, C. AND L. Pistaferri (2004): “Income Variance Dynamics and Heterogeneity," Econometrica, 72, 1-32. 
Melitz, M. J. (2003): “The Impact of Trade on Intra-Industry Reallocations and Aggregate Industry Productivity," Econometrica, 71, 1695-1725.

Mendes, R., G. J. VAn Den BerG, And M. Lindeboom (2010): “An empirical assessment of assortative matching in the labor market," Labour Economics, 17, 919-929.

POSTEL-VINAY, F. AND J.-M. ROBIN (2002): “Equilibrium wage dispersion with worker and employer heterogeneity," Econometrica, 70, 2295-2350.

SHimer, R. (2005): “The Assignment of Workers to Jobs in an Economy with Coordination Frictions," Journal of Political Economy, 113, 996-1025.

Shimer, R. AND L. SMith (2000): “Assortative Matching and Search,” Econometrica, 68, 343-370.

SYVERSON, C. (2011): “What Determines Productivity?" Journal of Economic Literature, 49, $326-65$.

TAtTARA, G. AND M. VAlEnTini (2007): “The cyclical behaviour of job and worker flows," Working Paper 16, Department of Economics, University of Venice "Ca' Foscari".

WoOdCOCK, S. D. (2010): "Heterogeneity and Learning in Labor Markets," The B.E. Journal of Economic Analysis \& Policy, 10, 1-69.

\section{A. Appendix}

\section{A.1 Institutional Background}

The period covered by our analysis is one of relative stability in the institutional setting of the Italian labor market. Major policy interventions aimed at liberalizing fixed term contracts were introduced only at the end of 2001 and in 2003, beyond our sample period.

Wage setting in Italy is governed by a "two-level" bargaining system. This system, introduced in 1993, replaced an earlier system that included local and sectoral agreements 
and a national indexation formula. ${ }^{33}$ Sectoral agreements (generally negotiated every two years) establish contractual minimum wages for different occupation classes (typically 7 or 8 sector-specific classes), that are automatically extended to all employees in the sector. Unions can also negotiate firm-specific contracts that provide wage premiums over the sectoral minimums. During the mid-1990s such firm-level agreements covered about $40 \%$ of private sector employees nationwide (see ISTAT [2000]). In addition, individual employees receive premiums and bonuses that add to the minimum contractual wage for their job. In our estimation sample nearly all employees earn at least some premium: the 5 th percentile of the percentage premium is $2.5 \%$, while the median is $24 \%$. The combination of sector and occupation minimum wages with individual-level wage premiums makes within-firm wage variability quantitatively significant. Lazear and Shaw [2009] report that within-firm wage variability in Italy represents about two thirds of total wage variability, in line with other countries described in their study.

During the mid-1990s Italy's employment protection legislation's index (EPL) was around the median of OECD countries, at a similar level to those of France and Germany (see Banca D'Italia [2002]). Moreover, the estimated job and worker turnover were in line with, if not higher than, similar European countries (see Contini and Trivellato [2005]).

The amount of labor turnover in this period is higher than expected by the content of the Italian labor code. A first reason for this lies in the peculiarity of the Italian industrial structure, characterized by a vast majority of small and very small firms. Firms with more than 15 employees could only fire individual workers with just cause: workers dismissed without a justifiable reason had the right to reinstatement. Because of the high diffusion of small firms, this rule did not apply to about $35 \%$ of employees. A second reason is that, even when the rule was applicable, it was commonly bypassed either legally by extrajudiciary settlements with severance payments, or by unlawful practices. ${ }^{34}$ Moreover, collective layoffs became available to firms employing more than 15 employees starting from 1991.35 Finally, labor jurists highlight that the "law in the books" and the "law in

\footnotetext{
${ }^{33}$ See Casadio [2004] and Dell'Aringa and Lucifora [1994]. The Netherlands, Spain, and Portugal have similar two-level systems.

${ }^{34}$ For example, forced quits that would go unreported to the judiciary for fear of losing job options offered within the same industrial district.

${ }^{35}$ Under collective layoffs, a firm can dismiss five or more employees within six months.
} 
Table 8: Estimates of the strength of sorting $\eta$ by subgroups

\begin{tabular}{c|cc|cc|cc|c}
\multirow{2}{*}{ Group } & \multicolumn{2}{|c|}{ Economic profits } & \multicolumn{2}{|c|}{ GOS } & \multicolumn{2}{|c|}{ AP } & \multirow{2}{*}{ ROE } \\
\cline { 2 - 7 } & per worker & total & per worker & total & per worker & total & \\
\hline All Workers & 0.526 & 0.520 & 0.527 & 0.523 & 0.510 & 0.530 & 0.523 \\
Men & 0.500 & 0.494 & 0.501 & 0.495 & 0.488 & 0.500 & 0.495 \\
Female & 0.588 & 0.581 & 0.587 & 0.588 & 0.567 & 0.600 & 0.588 \\
White Collar & 0.516 & 0.486 & 0.514 & 0.494 & 0.495 & 0.514 & 0.508 \\
Blue Collar & 0.528 & 0.531 & 0.530 & 0.532 & 0.516 & 0.536 & 0.527 \\
Aged 20-35 & 0.507 & 0.492 & 0.508 & 0.498 & 0.491 & 0.502 & 0.492 \\
Aged 35-50 & 0.505 & 0.514 & 0.500 & 0.510 & 0.482 & 0.520 & 0.526 \\
Aged 50-65 & 0.651 & 0.671 & 0.660 & 0.667 & 0.644 & 0.681 & 0.657 \\
\hline
\end{tabular}

All estimated $\eta$ are statistically significant: $\mathrm{p}$-values $<0.001$

action" may differ. This might be particularly relevant in the case of Italy, with its high number of laws and bylaws, sometimes patently contradictory, and amenable to dubious interpretations.

\section{A.2 Strength of Sorting by Subgroups}

Table 8 reports the estimates of the strength of sorting $\eta$ for different measures of profits and for different subgroups of workers. Estimated values are similar across subgroups, with higher values for the oldest workers (those aged 50 to 65) and for women.

\section{A.3 Heterogeneity in Unemployment Risk}

Expected wages may not reflect worker type if workers are heterogeneous in search ability. Workers of similar type $\varepsilon$ but different search ability possess different outside options. Therefore, they may get different wages, even when hired by the same firm right after unemployment. In this section we re-estimate $\gamma$ comparing coworkers who are similar in terms of search performance.

In order to control for search performance we exploit the full length of the VWH. We focus on the sub-sample of 1995-2001 movers who were active in the labor market before 1995. We reconstruct their labor market history going back to 1975 . We estimate equation (5) with controls for workers' past labor market histories. Controls include number 
Table 9: Sign of sorting controlling for Heterogeneity in Unemployment Risk

\begin{tabular}{l|cc|cc|ccc|c} 
& \multicolumn{2}{|c|}{ Economic profits } & \multicolumn{2}{|c|}{ GOS } & \multicolumn{2}{c|}{ AP } & \multirow{2}{*}{ ROE } \\
\cline { 2 - 7 } & $\mathrm{p}-\mathrm{w}$ & total & $\mathrm{p}-\mathrm{w}$ & total & $\mathrm{p}-\mathrm{w}$ & total & \\
\hline$\gamma$ & 0.035 & 0.055 & 0.030 & 0.049 & 0.023 & 0.034 & 0.026 \\
& $(0.004)$ & $(0.005)$ & $(0.004)$ & $(0.005)$ & $(0.004)$ & $(0.004)$ & $(0.004)$ \\
\hline Avg. Past Tenure & -0.032 & -0.019 & -0.031 & -0.022 & -0.029 & -0.023 & -0.016 \\
& $(0.003)$ & $(0.004)$ & $(0.003)$ & $(0.004)$ & $(0.003)$ & $(0.003)$ & $(0.003)$ \\
Avg. Unempl. Duration & 0.017 & 0.044 & 0.017 & 0.049 & 0.026 & 0.042 & 0.006 \\
& $(0.009)$ & $(0.010)$ & $(0.009)$ & $(0.010)$ & $(0.009)$ & $(0.008)$ & $(0.009)$ \\
Past Empl. Spells & 0.194 & 0.077 & 0.142 & 0.028 & -0.042 & -0.085 & -0.095 \\
& $(0.074)$ & $(0.082)$ & $(0.075)$ & $(0.084)$ & $(0.075)$ & $(0.071)$ & $(0.075)$ \\
Past Unempl. Spells & -0.253 & -0.223 & -0.184 & -0.141 & 0.023 & 0.035 & 0.065 \\
& $(0.085)$ & $(0.093)$ & $(0.085)$ & $(0.096)$ & $(0.086)$ & $(0.081)$ & $(0.085)$ \\
\hline
\end{tabular}

Number of observations is 89,007 . Controls for gender, age, age squared, migration status, tenure, tenure squared, year, and occupation are included in all regressions. Avg. Past Tenure is the average tenure in past employment spells $(\times 0.01)$. Avg. Unempl. Duration is average duration in past unemployment spells $(\times 0.01)$. Past Empl. Spells is the number of past employment spells $(\times 0.01)$. Past Unempl. Spells is the number of past unemployment spells $(\times$ 0.01). Sub-sample of 1995-2001 movers active in the labor market prior to 1995. Standard errors in parentheses.

of past employment spells, number of past unemployment spells, average duration of past employment spells, and average duration of past unemployment spells. After controlling for these additional sources of heterogeneity, the estimates of $\gamma$ remain positive and significant for all measures of profits (see Table 9).

\section{A.4 On-the-Job Search, Endogenous Search Intensity and Renegotiation}

Under renegotiation and endogenous search intensity, wages are not necessarily increasing on the worker type, not even within the firm (see Bagger and Lentz [2014]). In Lentz [2010] and Bagger and Lentz [2014], when a worker meets a potential employer, the current and poaching firms compete $\grave{a}$ la Bertrand for the worker, and the most productive firm wins. Were poaching and current firms identical, the worker would extract the full rent, obtaining a wage equal to the productivity of the match. We can use this last implication to rank workers within the firm by their types. For job-to-job transitions between firms of similar quality, the wage proxies the productivity of the match. Therefore, we fo- 
cus on the subsample of workers whose previous firm (not mediated by unemployment) is similar to the current firm. Of those, we pick coworkers who transition to a third firm through unemployment.

This exercise is demanding in terms of data. We select workers who transition at least three times. To illustrate this, denote some worker's employers chronologically as 1,2 and 3. We order workers by their wages in firm 2 . To do so we identify workers who move on-the-job to firm 2, coming from firms 1 similar to 2 . Next, we order employers by their next firm 3 . This sample trimming significantly reduces the number of valid observations to 16,870 .

We regress equation (6) in this subsample. We present results in Table 10. Transitions between two similar firms are defined as transitions without interim unemployment spell where the difference in rankings between previous and next firm is less than 0.10 in Columns (1) and (3) or below 0.05 in Columns (2) and (4). In all cases we find that better workers are more likely to move to better firms.

Table 10: Sign of Sorting with On-the-job Search and Renegotiation

\begin{tabular}{l|c|c|c|c}
\multirow{2}{*}{} & $(1)$ & $(2)$ & $(3)$ & $(4)$ \\
\cline { 2 - 5 } & \multicolumn{2}{|c|}{ Aggregated Profits } & \multicolumn{2}{c|}{ Profits per Worker } \\
\hline Difference in Ranking & $<0.10$ & $<0.05$ & $<0.10$ & $<0.05$ \\
\hline Wage $\times \mathbb{1}$ (Similar Firm) & 0.037 & 0.028 & 0.037 & 0.029 \\
& $(0.013)$ & $(0.011)$ & $(0.012)$ & $(0.012)$ \\
Wage $\times[1-\mathbb{1}$ (Similar Firm) $]$ & 0.041 & 0.031 & 0.042 & 0.032 \\
& $(0.013)$ & $(0.011)$ & $(0.012)$ & $(0.012)$ \\
\hline
\end{tabular}

Number of observations is 16,870 . Each column represents a single regression. In columns (1) and (2) firms are ordered in terms of economic profit, whereas in columns (3) and (4) they are ordered in terms of profit per worker. We include controls for gender, age, age squared, migration status, tenure, tenure squared, year, and occupation in all regressions. Firms fixed effects are included in every specification. All specifications consider workers who switch at least three times. $\mathbb{1}$ (Similar firm) is an indicator that takes a value of one if the worker comes from a firm similar to the firm where the wage is observed. Standard errors in parentheses. 
Table 11: Estimates of $\gamma$ (Sign of Sorting) with Detailed Occupation Controls

\begin{tabular}{cc|cc|cc|c}
\multicolumn{2}{c|}{ Economic profits } & \multicolumn{2}{c|}{ GOS } & \multicolumn{2}{c|}{ AP } & \multirow{2}{*}{ ROE } \\
\cline { 1 - 5 } per worker & total & per worker & total & per worker & total & \\
\hline 0.014 & 0.021 & 0.010 & 0.020 & 0.011 & 0.015 & 0.015 \\
$(0.006)$ & $(0.007)$ & $(0.006)$ & $(0.007)$ & $(0.006)$ & $(0.008)$ & $(0.006)$ \\
\hline
\end{tabular}

Number of observations is 114,871 . The dependent variable is the type of the previous firm before an unemployment spell. Each column represents a single regression. Controls for gender, age, age squared, migration status, tenure, tenure squared, year and occupation are included in all regressions. Firm $\times$ occupation fixed effects are included in every specification. Average number of workers in each firm $\times$ occupation cluster is 26.16 . Standard errors in parentheses.

\section{A.5 Detailed Occupation Categories}

Ideally, our test for the sign of sorting should be based on transitions of workers with identical jobs in the new firm. We include controls for broad occupation categories (blue collar, white collar and managers) in our results on Table 3. However, one concern with these estimates is that our occupational controls may be too broad. Detailed occupation classification such as ISCO is missing in our data set. In spite of this, we use detailed information on "job ladders" (livelli di inquadramento) within each industry-wide collective national contract to construct a more precise classification of jobs within firms. ${ }^{36}$ Although job ladders cannot be compared across different firms (they may be applying different national contracts), ladder codes can be used to identify workers doing similar jobs within the firm. Hence, we construct dummies identifying workers under the same national contract and job ladder code. We run our test including these more refined controls for occupation, instead of the firm dummies as in the previous tables. Table 11 shows the estimates of $\gamma$ in specifications that absorb a large number of effects by firm $\times$ (national contract $) \times($ job ladder) for different measures of profits. The results corroborate the presence of positive sorting: $\gamma$ is positive and significant in every specification.

\footnotetext{
${ }^{36}$ Each national contract specifies its own job-ladder and stipulates minimum wages for each of level of the ladder (typically, there are 7 to 9 levels in each job ladder).
} 


\section{A.6 Proof of Lemma 1}

First, we can express $\tau(p, \varepsilon)$ as follows:

$$
\begin{aligned}
\tau(p, \varepsilon) & =2 \int_{0}^{1} \int_{0}^{\varepsilon_{n}}\left[\operatorname{Pr}\left(p_{n}>p_{m} \mid \varepsilon_{n}, \varepsilon_{m}\right)-\operatorname{Pr}\left(p_{n}<p_{m} \mid \varepsilon_{n}, \varepsilon_{m}\right)\right] d \varepsilon_{m} d \varepsilon_{n} \\
& =2 \int_{0}^{1} \int_{0}^{\varepsilon_{n}}\left[2 \operatorname{Pr}\left(p_{n}>p_{m} \mid \varepsilon_{n}, \varepsilon_{m}\right)-1\right] d \varepsilon_{m} d \varepsilon_{n}
\end{aligned}
$$

And similarly,

$$
\begin{aligned}
\tau(p, w)= & 2 \int_{0}^{1} \int_{0}^{\varepsilon_{n}}\left[\operatorname{Pr}\left(w_{n}>w_{m}, p_{n}>p_{m} \mid \varepsilon_{n}, \varepsilon_{m}\right)+\operatorname{Pr}\left(w_{n}<w_{m}, p_{n}<p_{m} \mid \varepsilon_{n}, \varepsilon_{m}\right)\right. \\
& \left.-\operatorname{Pr}\left(w_{n}>w_{m}, p_{n}<p_{m} \mid \varepsilon_{n}, \varepsilon_{m}\right)-\operatorname{Pr}\left(w_{n}<w_{m}, p_{n}>p_{m} \mid \varepsilon_{n}, \varepsilon_{m}\right)\right] d \varepsilon_{m} d \varepsilon_{n} \\
= & 2 \int_{0}^{1} \int_{0}^{\varepsilon_{n}}\left[\operatorname{Pr}\left(w_{n}>w_{m} \mid \varepsilon_{n}, \varepsilon_{m}\right)\left[\operatorname{Pr}\left(p_{n}>p_{m} \mid \varepsilon_{n}, \varepsilon_{m}\right)-\operatorname{Pr}\left(p_{n}<p_{m} \mid \varepsilon_{n}, \varepsilon_{m}\right)\right]\right. \\
& \left.-\operatorname{Pr}\left(w_{n}<w_{m} \mid \varepsilon_{n}, \varepsilon_{m}\right)\left[\operatorname{Pr}\left(p_{n}>p_{m} \mid \varepsilon_{n}, \varepsilon_{m}\right)-\operatorname{Pr}\left(p_{n}<p_{m} \mid \varepsilon_{n}, \varepsilon_{m}\right)\right]\right] d \varepsilon_{m} d \varepsilon_{n}
\end{aligned}
$$

Then,

$$
\tau(p, w)=2 \int_{0}^{1} \int_{0}^{\varepsilon_{n}}\left[2 \operatorname{Pr}\left(w_{n}>w_{m} \mid \varepsilon_{n}, \varepsilon_{m}\right)-1\right]\left[2 \operatorname{Pr}\left(p_{n}>p_{m} \mid \varepsilon_{n}, \varepsilon_{m}\right)-1\right] d \varepsilon_{m} d \varepsilon_{n}
$$

Next, recall that $v_{i}$ are i.i.d. Then, for all $\varepsilon_{n}>\varepsilon_{m}, \operatorname{Pr}\left(p_{n}>p_{m} \mid \varepsilon_{n}, \varepsilon_{m}\right) \geq \frac{1}{2} \Leftrightarrow \alpha \geq 0$. As a

result, $\operatorname{sign}(\tau(p, \varepsilon))=\operatorname{sign}(\alpha)$. For all $\varepsilon_{n}>\varepsilon_{m}, \operatorname{Pr}\left(w_{n}>w_{m} \mid \varepsilon_{n}, \varepsilon_{m}\right)>\frac{1}{2}$. Then, in (12), $2 \operatorname{Pr}\left(w_{n}>w_{m} \mid \varepsilon_{n}, \varepsilon_{m}\right)-1>0$. So $\operatorname{sign}(\tau(p, w))=\operatorname{sign}(\alpha)$. Next,

$$
\begin{aligned}
|\tau(p, w)| & \leq 2 \int_{0}^{1} \int_{0}^{\varepsilon_{n}}\left|2 \operatorname{Pr}\left(w_{n}>w_{m} \mid \varepsilon_{n}, \varepsilon_{m}\right)-1\right|\left|2 \operatorname{Pr}\left(p_{n}>p_{m} \mid \varepsilon_{n}, \varepsilon_{m}\right)-1\right| d \varepsilon_{m} d \varepsilon_{n} \\
& \leq 2 \int_{0}^{1} \int_{0}^{\varepsilon_{n}}\left|2 \operatorname{Pr}\left(p_{n}>p_{m} \mid \varepsilon_{n}, \varepsilon_{m}\right)-1\right| d \varepsilon_{m} d \varepsilon_{n}=|\tau(p, \varepsilon)|
\end{aligned}
$$

Next, let $Y$ and $X$ be random variables. $Y$ is left tail decreasing in $X$ if $\operatorname{Pr}(Y \leq y \mid X \leq x)$ is a non-increasing function of $x$ for all $y$. Similarly, $Y$ is right tail increasing in $X$ if $\operatorname{Pr}(Y>y \mid X>x)$ is a non-decreasing function of $x$ for all $y$. Take random variables $p$ and $\varepsilon$ as expressed in equation (9). Take $\alpha>0$. Then,

$\operatorname{Pr}(P \leq p \mid \tilde{\varepsilon} \leq \varepsilon)=\operatorname{Pr}\left(\alpha \psi_{p}(\tilde{\varepsilon})+v_{i} \leq p \mid \tilde{\varepsilon} \leq \varepsilon\right)=\operatorname{Pr}\left(v_{i} \leq p-\alpha \psi_{p}(\tilde{\varepsilon}) \mid \tilde{\varepsilon} \leq \varepsilon\right)$ 


$$
=\left[\int_{0}^{\varepsilon} \operatorname{Pr}\left(v_{i} \leq p-\alpha \psi_{p}(\tilde{\varepsilon})\right) d \tilde{\varepsilon}\right]\left(\int_{0}^{\varepsilon} d \tilde{\varepsilon}\right)^{-1}=\left[\int_{0}^{\varepsilon} \operatorname{Pr}\left(v_{i} \leq p-\alpha \psi_{p}(\tilde{\varepsilon})\right) d \tilde{\varepsilon}\right] \varepsilon^{-1}
$$

Then,

$$
\begin{aligned}
\frac{\partial \operatorname{Pr}(P \leq p \mid \tilde{\varepsilon} \leq \varepsilon)}{\partial \varepsilon} & =\operatorname{Pr}\left(v_{i} \leq p-\alpha \psi_{p}(\varepsilon)\right) \varepsilon^{-1}+\left[\int_{0}^{\varepsilon} \operatorname{Pr}\left(v_{i} \leq p-\alpha \psi_{p}(\tilde{\varepsilon})\right) d \tilde{\varepsilon}\right](-1) \varepsilon^{-2} \\
& =\varepsilon^{-1}\left[\operatorname{Pr}\left(v_{i} \leq p-\alpha \psi_{p}(\varepsilon)\right)-\left[\int_{0}^{\varepsilon} \operatorname{Pr}\left(v_{i} \leq p-\alpha \psi_{p}(\tilde{\varepsilon})\right) d \tilde{\varepsilon}\right] \varepsilon^{-1}\right]<0
\end{aligned}
$$

since $\operatorname{Pr}\left(v_{i} \leq p-\alpha \psi_{p}(\varepsilon)\right)$ is decreasing in $\varepsilon$. Similarly,

$$
\begin{aligned}
\operatorname{Pr}(P>p \mid \tilde{\varepsilon}>\varepsilon) & =\operatorname{Pr}\left(\alpha \psi_{p}(\tilde{\varepsilon})+v_{i}>p \mid \tilde{\varepsilon}>\varepsilon\right) \\
& =\left[\int_{\varepsilon}^{1} \operatorname{Pr}\left(v_{i}>p-\alpha \psi_{p}(\tilde{\varepsilon})\right) d \tilde{\varepsilon}\right](1-\varepsilon)^{-1}
\end{aligned}
$$

Then,

$$
\begin{aligned}
\frac{\partial \operatorname{Pr}(P>p \mid \tilde{\varepsilon}>\varepsilon)}{\partial \varepsilon}=- & {\left[\operatorname{Pr}\left(v_{i}>p-\alpha \psi_{p}(\varepsilon)\right)\right](1-\varepsilon)^{-1} } \\
& +\left[\int_{\varepsilon}^{1} \operatorname{Pr}\left(v_{i}>p-\alpha \psi_{p}(\tilde{\varepsilon})\right) d \tilde{\varepsilon}\right](-1)(1-\varepsilon)^{-2}(-1) \\
= & (1-\varepsilon)^{-1}\left[-\operatorname{Pr}\left(v_{i}>p-\alpha \psi_{p}(\varepsilon)\right)+\frac{\int_{\varepsilon}^{1} \operatorname{Pr}\left(v_{i}>p-\alpha \psi_{p}(\tilde{\varepsilon})\right) d \tilde{\varepsilon}}{1-\varepsilon}\right]>0
\end{aligned}
$$

since $\operatorname{Pr}\left(v_{i}>p-\alpha \psi_{p}(\varepsilon)\right)$ is increasing in $\varepsilon$.

Finally, take the case $\alpha>0$. Then, the random variable $p$ is both left tail increasing and right tail increasing in $\varepsilon$. Then, by Proposition 2.3. in Capéraà and Genest [1993], $\rho(p, \varepsilon) \geq \tau(p, \varepsilon) \geq 0$. The case $\alpha \leq 0$ can be shown similarly.

\section{A.7 AKM Correlation}

In their influential contribution, Abowd et al. [1999] assign worker and firm types through the estimation of worker and firm fixed effects from standard Mincer-type wage equations. Then they make inference on the sign and strength of sorting through the correlation between these fixed effects. Longitudinal matched employer-employee data, where workers are observed as they move across different employers, is required for this ap- 
proach. Abowd et al. find that the correlation between the worker fixed effect and the firm fixed effect is insignificant or even negative, implying that positive assortative matching plays little role in the labor market.

In this section we report results using the strategy presented in Abowd et al. [1999]. We first estimate the following wage equation:

$$
w_{i, j, t}=x_{i, j, t}^{\prime} \beta+\vartheta_{i}+\xi_{j}+z_{i, j, t}
$$

where $x_{i, j, t}$ are observable and time-varying characteristics of the worker and the firm, $\vartheta_{i}$ is worker $i$ fixed effect and $\xi_{j}$ is firm $j$ fixed effect. The dependent variable is the worker's daily wage and the time-varying controls include a quadratic in the worker's age, a quadratic in the worker's tenure with the current employer, indicators for whitecollar and managerial occupations, indicators for five firm-size classes and year effects. The results are presented in Table 12. As reported by many other replications of the classical Abowd et al.'s result, we too find evidence of a small negative correlation (-0.02) between the worker fixed effects and the firm fixed effects. Moreover, this correlation is statistically significant in our data set.

Table 12: AKM Approach: OLS Estimates of Equation (13)

\begin{tabular}{l|cc}
$y=\log ($ wages $)$ & Coefficient & Std-Dev. \\
\hline Age & 0.0486 & $(0.00018)$ \\
Age $^{2}$ & -0.0004 & $\left(2.34 \times 10^{-6}\right)$ \\
Tenure & 0.0006 & $(0.000013)$ \\
Tenure & $-1.43 \times 10^{-6}$ & $\left(5.90 \times 10^{-8}\right)$ \\
White-Collar & 0.0510 & $(0.000734)$ \\
Manager & 0.2879 & $(0.003016)$ \\
\multicolumn{2}{|c}{ Std. dev. of person effects $\vartheta_{i}$ (across person year obs) $=0.320$} \\
\multicolumn{2}{c}{ Std. dev. of firm effects $\xi_{j}$ (across person year obs) $=0.151$} \\
\multicolumn{2}{c}{ Correlation $\left(\xi_{j}, \vartheta_{i}\right)=-0.0216$ with p-value $<0.0001$} \\
\hline \hline
\end{tabular}

Note: Number of observations is 2,672,812. Number of workers is 778,388. Number of firms is 11,985 . Year dummies and dummies for firm size (5 categories) included. The sample covers the period 1995-2001.

Abowd et al.'s strategy can generate inconsistent results for a number of reasons. Mean wages provide a noisy ranking of workers. If i.i.d., this noise biases the correlation 
toward zero. However, as described in Section 5, the noise in the estimate of worker i's mean wages is potentially correlated with worker i's employers' types. If so, the direction of the bias is undetermined.

Second, there is also noise in the ranking of firms. The estimated covariance can be biased if the noise in the estimated ranking of workers and the noise in the estimated ranking of firms are correlated. Andrews, Gill, Schank, and Upward [2008] and Abowd, Kramarz, Lengerman, and Perez-Duarte [2004] find that, although the bias can be considerable, it is not sufficiently large to remove the negative correlation in data sets from Germany, France and the United States.

Third, as pointed out by Gautier and Teulings [2006], Eeckhout and Kircher [2011] and Lopes de Melo [2013], firm fixed effects estimated from wage equations do not necessarily reflect the firms' underlying types. Whenever wages are non-monotone in firm type, the linear model in Abowd et al. [1999] is fundamentally misspecified. Gautier and Teulings [2006] present evidence of wages non-monotonicity in the firm type for five European countries and the United States. Next, we present evidence suggesting that wages are also non-monotone in the firm type in our data.

We show that workers who move to better firms may obtain either a wage gain or a wage cut (and also workers moving to worse firms). Movements across firms and the resulting wage changes can be easily observed in our data set. The results are presented in Table 13.

We find suggestive evidence of non-monotonicity of wages in the firm type. There is an association between positive changes in the firm type and positive changes in wages. However, we observe a large number of workers moving to worse firms where they receive higher wages, and workers that end up in a better firm receiving lower wages. If we consider only job-to-job movers with stable jobs ${ }^{37}, 36 \%$ of movers switching to a better firm end up receiving a wage decrease and $60 \%$ of movers switching to a worse firm get a wage increase. ${ }^{38}$

\footnotetext{
${ }^{37}$ This sample selection aims at reducing noise, but the same patterns are true for different groups of movers (see Table 13). Job-to-Job movements are defined as movements between two consecutive employment spells with less than 1 month of unemployment in between. Stable jobs are defined as employment spells that last at least one year.

${ }^{38}$ In the tabulations presented in Table 13, we observe a large number of workers moving to jobs with
} 


\section{Table 13: Wages Non Monotone in the Firm Type}

\begin{tabular}{c|c|cc|cc}
\multicolumn{2}{c|}{} & \multicolumn{2}{|c|}{ All Transitions } & Job-to-Job Movers \& Stable Jobs \\
\cline { 3 - 6 } \multicolumn{2}{c|}{} & Worse Wage & Better Wage & Worse Wage & Better Wage \\
\hline \multirow{2}{*}{$(1)$} & Worse Firm & 49,381 & 55,467 & 7,752 & 12,032 \\
& Better Firm & 47,680 & 70,905 & 9,086 & 15,854 \\
\hline \multirow{2}{*}{$(2)$} & Worse Firm & 50,105 & 56,338 & 8,260 & 13,040 \\
& Better Firm & 46,956 & 70,034 & 8,578 & 14,846 \\
\hline
\end{tabular}

Notes: In row (1) firms are ordered by profits per worker. In row (2) firms are ordered by total profits. Change in wages is calculated as the difference between the average daily wages in two consecutive spells. Job-to-Job movers are defined as movements between two consecutive spells with less than 1 month of unemployment in between. Stable jobs are defined as spells that last at least one year.

lower wages. When only considering job-to-job movements, this proportion is significantly smaller, but still large. The presence of job-related amenities is one potential candidate to explain this pattern. A second possible explanation for job-to-job transitions with wage cuts is the existence of on-the-job search and renegotiation (Postel-Vinay and Robin [2002]). Measurement error is also a potential candidate to explain wage cuts. 